\title{
Metodología analítica para la determinación de oxiesteroles
}

\author{
Por F. Guardiola, R. Codony, M. Rafecas y J. Boatella \\ Unidad de Nutrición y Bromatología. Departamento de Ciencias Fisiológicas Humanas y de la Nutrición. \\ Facultad de Farmacia. Universidad de Barcelona. Av. Joan XXIII, s/n 08028 - Barcelona.
}

\section{RESUMEN}

\section{Metodología analítica para la determinación de oxiesteroles}

El presente trabajo recoge los principales aspectos relacionados con el análisis de los derivados oxidados del colesterol. Este problema analítico es relativamente reciente y muchas cuestiones relacionadas con el mismo son controvertidas. Prueba de ello es la existencia de un número elevado de metodologías, que exigen aún, en muchos casos, una mejora y validación. Por ello, se ha creido interesante una discusión de los principales sistemas propuestos para su determinación (cromatografía de gases y cromatografía de alta eficacia), así como de las etapas previas de extracción y purificación de las muestras.

PALABRAS-CLAVE: Información (artículo) - Método de análisis Oxiesterol.

\section{SUMMARY}

\section{Analytical methods of oxysterol determination}

This paper deal with the main aspects of the analysis of oxysterols. This analytical problem is quite new and many questions involved are still controversial. Consequently, many methodologies exist that still need improvement and standarization. Therefore, it is interesting to discuss the analytical methodologies proposed by different authors for the extraction, purification and determination (gas chromatography and high performance liquid chromatography) of oxysterols.

KEY-WORDS: Analytical method - Information (paper) - Oxysterol.

\section{INTRODUCCION.}

Los derivados oxidados del colesterol se conocen desde principios de siglo, pero su presencia en alimentos (Acker y Greve, 1963) y sus implicaciones toxicológicas (Bischoff, 1969) se detectaron por primera vez durante los años 60, momento en el cual se planteó la necesidad de analizar la presencia de estos compuestos, básicamente, en alimentos, modelos experimentales y arterias, sangre y suero humanos.

El análisis de estos compuestos presenta una serie de problemas que son básicamente los siguientes:

- IOs OE son compuestos con una gran similitud estructural lo que requiere una elevada resolución por parte del método analítico;

- estos derivados oxidados se presentan en cantidades muy pequeñas, lo cual implica que el método debe caracterizarse por presentar una elevada sensibilidad;

- los alimentos y muestras procedentes de seres vivos poseen fracciones lipídicas muy complejas, donde los OE se encuentran a nivel traza, lo cual hace necesaria una purificación exhaustiva de estos compuestos;

- los OE se forman fácilmente a partir del colesterol y, a la vez, algunos de ellos son altamente inestables, con lo cual hay que poner especial atención a la formación de artefactos durante la manipulación de las muestras y el procedimiento analítico.

Todos estos problemas hacen que el análisis de estos compuestos sea altamente controvertido y que exista un número muy elevado de metodologías para llevarlo a cabo. Esta situación de controversia lleva a cuestionar la validez de muchas de estas metodologías y a seguir trabajando en la mejora y validación de estos métodos analíticos.

La gran mayoría de los métodos de análisis de OE suelen presentar las siguientes etapas:

- extracción de la fracción lipídica;

- purificación de los OE presentes en esta fracción;

- separación, identificación y cuantificación cromatográfica de los $\mathrm{OE}$;

- confirmación de la identificación por EM.

\section{EXTRACCION DE LA FRACCION LIPIDICA.}

Los OE compuestos minoritarios de la fracción lipídica de algunos alimentos se encuentran entre los componentes más polares de dicha fracción. Algunos autores han comprobado que la mezcla CLO/MET $(2: 1, \mathrm{v} / \mathrm{v})$ ( ver abreviaturas tabla I) es la más efectiva para extraer, al mismo tiempo, grasa total y compuestos polares como el colesterol de ciertos alimentos, entre los que se encuentra el huevo (Hubbard et al., 1977; Kaneda et al., 1980). Por otro lado, para la extracción de lípidos totales en alimentos y muestras de origen biológico, uno de los procedimientos de extracción más extendidos es el de Folch et al. (1957), que 
consiste en agitar la muestra en la mezcla CLO/MET (2:1, $\mathrm{v} / \mathrm{v})$. Este es el procedimiento más comúnmente empleado para extraer la fracción lipídica y, a continuación, sobre ella realizar el análisis de OE (tabla II). No obstante, algunos autores han preferido la homogeneización con otros disolventes tales como, acetona, ACE (Kou y Holmes, 1985), CLO, HEX/ISO (3:2 ó1:2, v/v), etanol/diclorometano (1:1, $\mathrm{v} / \mathrm{v}$ ) y éter metilterbutílico. En algunos trabajos a las mezclas de disolventes se les añade una pequeña proporción de antioxidante (tabla II).

Por otro lado, en algunos trabajos recientes, la extracción de los $O E$ de la carne se realiza eluyendo con cloruro de metileno/MET (9:1, v/v) (Higley et al., 1986) o con fracciones de polaridad creciente (Zubillaga y Maerker, 1991), una columna formada por una base de $\mathrm{CaHPO}_{4}-2 \mathrm{H}_{2} \mathrm{O}+$ Celita 545 (Higley et al., 1986) o de $\mathrm{CaHPO}_{4}-2 \mathrm{H}_{2} \mathrm{O}+$ Celita 545 + gel de silice (Zubillaga y Maerker, 1991) sobre la cual se deposita un triturado de la muestra con sulfato sódico anhidro + Celita 545. Fontana et al. también en un trabajo reciente (1992), extrajeron los OE de la yema de huevo en polvo depositando la muestra en la parte superior de una columna de gel de sílice, sobre la muestra se dispuso una fina capa de gel de sílice y se eluyó la columna con fracciones de polaridad creciente. Con este sistema de extracción se consigue un fraccionamiento de los lípidos de la muestra, constituyendo esta etapa una primera purificación en la que se recogen los eluatos más polares que contienen los OE y se descartan los más apolares que contienen TG y la mayor parte del colesterol (Fontana et al., 1992; Zubillaga y Maerker, 1991), mientras que los FL quedan retenidos mayoritariamente en la columna (Zubillaga y Maerker, 1991).

El hexano ha sido utilizado para extraer la fracción lipídica en el análisis de OE en mantequilla (Parks et al., 1966) y leche en polvo desnatada (Flanagan et al., 1975). No obstante, algunos de los oxiesteroles más polares como el CT son poco solubles en disolventes apolares como el éter de petróleo o el hexano, con lo cual es cuestionable la extracción de la fracción lipídica con estos disolventes para el análisis de OE. Además, en el caso de la mantequilla se suele omitir la fase de extracción, pasándose directamente a la saponificación.

\section{PURIFICACION DE LOS OXIESTEROLES.}

Como ya hemos señalado, los OE en caso de estar presentes en la fracción lipídica lo están a nivel traza. Este hecho hace necesaria una purificación de los OE más o menos exhaustiva en función de la muestra, lo cual contribuye al aumento de sensibilidad del método analítico. Esta purificación puede conseguirse con la aplicación aislada o combinada de saponificación, cromatografía en columna y/o CCF.

\subsection{SAPONIFICACION.}

La saponificación en el análisis de OE se aplica normalmente sobre la fracción grasa, aunque en algunos casos se realiza directamente sobre la muestra, omitiéndose la etapa de extracción lipídica (Doormaal et al., 1989; Gruenke et al., 1987; Naber y Bigger, 1985; Koopman et al., 1987;). Según Bascoul et al. (1986) una saponificación no suficientemente enérgica implica la necesidad de una purificación previa a la determinación cromatográfica de los $\mathrm{OE}$, cosa que no es necesaria cuando la saponificación se lleva a cabo con $\mathrm{KOH}$ metanólica en caliente durante $2 \mathrm{hr}$. La saponificación en caliente ha sido empleada por diversos autores (tabla II) pero paulatinamente se va sustituyendo por la saponificación en frío. La razón de esta sustitución se encuentra en la demostración por parte de diversos autores de la inestabilidad del 7-CC y colesterol$5 \alpha, 6 \alpha$-epóxido en caliente y en medio alcalino.

Esta inestabilidad del 7-CC alcalino se conoce desde hace muchos años, cuando Bergström y Wintersteiner (1941) señalaron que este compuesto se descomponía básicamente en colesta-3,5-dien-7-ona. Posteriormente, otros autores confirmaron esta observación (Chicoye et al., 1968b, c; Higley et al., 1986; Maerker y Unruh, 1986).

Algunos trabajos concluyen que en caliente y en medio alcalino se produce descomposición del $\alpha-$ CE en CT por hidrólisis del anillo epóxido. Así, por ejemplo, en un trabajo de Tsai et al. (1980) se observa que la recuperación del $\alpha$-CE tras la saponificación con $\mathrm{KOH}$ metanólica en caliente es tan sólo del $25 \%$.

Estos problemas de estabilidad con el 7-CC y $\alpha-C E$, según una serie de trabajos, no se presentan con la saponificación en frío. Así, diversos autores que aplican este método de saponificación obtuvieron recuperaciones buenas para estos dos compuestos (Chicoye et al., 1968a; Park y Addis, 1986a, Pie et al., 1990). No obstante, la controversia se inicia con los resultados de Van de Bovenkamp et al. (1988) según los cuales el 7-CC se recupera entre un $11-40 \%$ tras la saponificación en frío y no se recupera tras la saponificación en caliente.

A pesar de estos resultados de Van de Bovenkamp existe un hecho evidente y es que el análisis del contenido de OE en diversos alimentos, mediante métodos en los que se aplica la saponificación en frío, da como resultado que el OE mayoritario es el 7-CC y, por otro lado, no aparece la colesta-3,5-dien-7-ona.

La colesta-3,5-dien-7-ona se encuentra entre los derivados oxidados que se forman a partir del colesterol cuando éste se calienta (Korahani et al., 1981; Nawar et al. 1991), pero es un compuesto que se ha detectado en pocas ocasiones en alimentos y cuando esto ha sucedido ha sido, normalmente, mediante métodos que aplican la saponificación en caliente (Bascoul et al., 1986; Pennock et al., 1962; Ryan et al., 1981). 
Tabla I

Abreviaturas utilizadas en este trabajo

\begin{tabular}{|c|c|c|c|}
\hline aa & Aminoácidos & 20-HC & 20-HidroxiColesterol ${ }^{\mathrm{a}}$ \\
\hline ACE & Acetonitrilo & $20 \alpha-H C$ & $20 \alpha$-HidroxiColesterol \\
\hline BUT & Butanol & 20S-HC & (20S)-20-HidroxiColesterol \\
\hline CB & Cloruro de Benzoilo & $22 \mathrm{~S}-\mathrm{HC}$ & (22S)-22-HidroxiColesterol \\
\hline $\mathrm{CC}$ & Columna Capilar & 23R-HC & (23R)-23-HidroxiColesterol \\
\hline $\mathrm{CCF}$ & Cromatografía en Capa Fina & 24R-HC & (24R)-24-HidroxiColesterol \\
\hline 7-CC & 7-CetoColesterol ${ }^{\mathrm{a}}$ & 24S-HC & (24S)-24-HidroxiColesterol \\
\hline $22-\mathrm{CC}$ & 22-CetoColesterol ${ }^{\mathrm{a}}$ & $25-\mathrm{HC}$ & 25-HidroxiColesterol ${ }^{\mathrm{a}}$ \\
\hline 6-CCL & 6-CetoCoLestanol ${ }^{a}$ & (25R)-26-HC & (25R)-26-HidroxiColesterol \\
\hline 7-CCL & 7-CetoCoLestanol ${ }^{a}$ & 26R-HC & (26R)-26-HidroxiColesterol \\
\hline 22-CCL & 22-CetoCoLestanol & 26S-HC & (26S)-26-HidroxiColesterol \\
\hline $\mathrm{CE}$ & Colesterol-5,6-Epóxido & HEX & Hexano \\
\hline CEs & Colesterol-5,6-Epóxidos & $7 \alpha-\mathrm{HPC}$ & $7 \alpha$-HidroPeroxiColesterol \\
\hline$\alpha-\mathrm{CE}$ & Colesterol-5 $\alpha, 6 \alpha$-Epóxido ${ }^{a}$ & 7B-HPC & 7B-HidroPeroxiColesterol \\
\hline B-CE & Colesterol-5ß,6ß-Epóxido ${ }^{a}$ & $7 \alpha-\mathrm{HS}$ & $7 \alpha$-HidroxiSitosterol \\
\hline $5 \alpha-C L$ & $5 \alpha$-CoLestano ${ }^{a}$ & 7B-HS & 7ß-HidroxiSitosterol \\
\hline CG & Cromatografía de Gases & IR & Espectroscopía Infrarroja \\
\hline CG-EM & $\begin{array}{l}\text { Cromatografía de gases- } \\
\text { Espectrometría de Masas }\end{array}$ & ISO & Isopropanol \\
\hline CLAE & $\begin{array}{l}\text { Cromatografía Líquida de Alta } \\
\text { Eficacia }\end{array}$ & LD & Límite de Detección \\
\hline CLO & Cloroformo & LC & Límite de Cuantificación \\
\hline $\mathrm{CoC}$ & CoCromatografía & MET & Metanol \\
\hline CR & Columna de Relleno & ND & No Detectado \\
\hline CT & ColestanTriol $^{\mathrm{a}}$ & NS & No Significativo(a) \\
\hline DIL & Detector de Ionización de Llama & OE & OxiEsterol(es) \\
\hline EM & Espectrometría de Masas & PI & Patrón Interno \\
\hline FL & FosfoLípidos & RMN & $\begin{array}{l}\text { Espectroscopía de Resonancia } \\
\text { Magnética Nuclear }\end{array}$ \\
\hline FM & Fase Móvil & $\alpha$-SE & Sitosterol-5 $\alpha, 6 \alpha$-Epóxido \\
\hline FRR & Factor(es) de Respuesta Relativo(s) & B-SE & Sitosterol-5ß,6ß-Epóxido \\
\hline GT & Grasa Total & TEAP & TriEtilAminohidroxiPropil \\
\hline 4ß-HC & 4ß-HidroxiColesterol & TMS & $\begin{array}{l}\text { Derivatización en forma de } \\
\text { TriMetilSilil éteres }\end{array}$ \\
\hline 7-HC & 7-HidroxiColesterol & TG & TriGlicéridos \\
\hline 7-HCs & 7-HidroxiColesteroles & TR & Tiempo de Retención \\
\hline $7 \alpha-\mathrm{HC}$ & $7 \alpha$-HidroxiColesterol ${ }^{a}$ & UV & Espectrofotometría Ultravioleta \\
\hline 7ß-HC & 7B-HidroxiColesterol ${ }^{\mathrm{a}}$ & $*$ & $\begin{array}{l}\text { Marca inicio programa de } \\
\text { temperatura de horno }\end{array}$ \\
\hline 19-HC & 19-HidroxiColesterol & & \\
\hline
\end{tabular}

${ }^{a}$ El nombre sistemático de este compuesto aparece en la tabla IV. 
Por otro lado, también existe controversia alrededor de si la saponificación en caliente implica o no la formación de derivados oxidados a partir del colesterol. Según Bascoul et al. (1986) la saponificación en caliente con $\mathrm{KOH}$ metanólica $1 \mathrm{~N}$ durante $2 \mathrm{hr}$ no implica oxidación del colesterol, en cambio otros autores señalan la oxidación del colesterol durante la saponificación en caliente (Maerker y Unruh, 1986; Naber y Bigger, 1985). Según diversos autores esta oxidación no tiene lugar cuando la saponificación es en frío (Pie y Seillan, 1992; Pie et al., 1990). No obstante, Maerker y Unruh (1986) señalaron la formación de pequeñas cantidades de OE incluso en un método en el que no se realizaba saponificación. En este último trabajo se comprobó que esta formación no se evitaba ni en presencia de BHT ni de otros antioxidantes fenólicos.

Sean cuales sean las condiciones bajo las que se efectúe la saponificación, la extracción de la materia insaponificable se realiza mayoritariamente con éter etílico, aunque Bascoul et al. (1986) la realizaron con diclorometano.

\subsection{CROMATOGRAFIA EN COLUMNA.}

La cromatografía en columna para purificar los OE se puede aplicar directamente sobre los lípidos totales procedentes de la extracción o sobre la materia insaponificable procedente de la saponificación. Además, tras esta fase se puede pasar a una posterior purificación o directamente a la determinación cromatográfica (tabla II).

El tipo de cromatografía en columna más usada es la de adsorción con gel de sílice, en este caso la purificación se consigue eluyendo la columna con fracciones de polaridad creciente (tabla II) y de esta manera los componentes de la fracción lipídica eluyen en el siguiente orden: ésteres del colesterol, TG, colesterol libre, OE y FL. En algún trabajo, con este sistema se consiguen incluso separar los diferentes $O E$ en función de su polaridad. Este es el caso del trabajo de Van de Bovenkamp et al. (1988) en el que se realizó la purificación con dos columnas de gel de silice. La fracción lipídica extraída de la muestra se redisolvió en CLO y se aplicó sobre la primera de estas columnas, el colesterol esterificado y los TG fueron eluidos con $175 \mathrm{ml}$ de CLO y el colesterol libre y los OE lo fueron con $150 \mathrm{ml}$ de acetona. Los FL quedaron retenidos en la columna. Los $150 \mathrm{ml}$ de acetona se èvaporaron y el residuo seco se redisolvió en 3 $\mathrm{ml}$ de CLO/acetona (98:2, v/v) que se aplicaron sobre la segunda columna de gel de sílice. La columna se eluyó con $100 \mathrm{ml}$ de cada una de las siguientes mezclas CLO/acetona: A $(98: 2, v / v), B(80: 20, v / v)$ y $C(50: 50, v / v)$. Con la fracción A eluyeron colesterol y colestanol; con la $\mathrm{B}, 25-\mathrm{HC}$, $\alpha-C E, 7-C C$ y la mayor parte de 7B-HC; y con la C, CT y una pequeña cantidad de 7B-HC. La fracción $A$ se descartó y en las otras dos fracciones se determinó, por separado, el contenido en OE mediante CG. Ultimamente, se tiende al uso de minicolumnas para esta purificación (tabla II). La purificación con columna de gel de sílice puede ir precedida de saponificación o seguida de otra purificación (tabla II). No obstante, actualmente, cada vez es más frecuente que sea la única etapa de purificación en los métodos analíticos, incluso cuando se trabaja con mezclas tan complejas como los provenientes del huevo y ovoproductos (tabla II).

Otro de los tipos de cromatografía en columna capaz de separar los OE de los FL y TG es la de exclusión molecular. Esta cromatografía ha sido aplicada recientemente al análisis de $\mathrm{OE}$. Los primeros en utilizarla (columna de Lipidex-5000) asociada a la cromatografía de intercambio iónico (columna de TEAP-Lipidex) fueron NouroozZadeh y Appelqvist (1987). Posteriormente, estos mismos autores asociaron una cromatografía con cartucho de gel de sílice (Sep-Pak) a los dos tipos de cromatografía citados anteriormente (Nourooz-Zadeh y Appelqvist 1988a, 1989). En relación con la cromatografía de exclusión Nawar et al. (1991) comprobaron que era efectiva, pero que, sin embargo, requería mucho tiempo (columna de Styragel).

Otra modalidad de cromatografía en columna que ha sido utilizada por algunos autores y siempre asociada a otros sistemas de purificación es la secuestrante o de argentación (columna de Florisil- $\mathrm{AgNO}_{3}$ ) (tabla II).

Finalmente, otro sistema de purificación, aunque no tan habitual es la CLAE preparativa. Este sistema fue utilizado por Csiky (1982) previamente a la determinación de los OE por CLAE y por Missler et al. (1985) asociado a la cromatografía en columna de gel de sílice también de forma previa la determinación de los OE por CLAE. Fontana et al. (1992), utilizaron la doble CLAE preparativa para la determinación de los OE por RMN.

\subsection{CROMATOGRAFIA EN CAPA FINA PREPARATIVA.}

La CCF con gel de sílice ha sido ampliamente utilizada para aislar los esteroles del resto de la fracción lipídica y por tanto también se ha aplicado en la determinación de OE. En función de la elución utilizada se separan, o no, los OE del colesterol y los esteroles vegetales. Pie en sus distintos trabajos mediante CCF consiguió separar los oxiesteroles del colesterol (Pie y Seillan, 1992; Pie et al., 1990, 1991) y lo mismo consiguieron Finocchiaro et al. (1984).

En algunos trabajos, mediante esta técnica, se fraccionaron incluso los oxiesteroles (figura 1) (Pie y Seillan, 1992; Pie et al., 1991).

\section{SEPARACION, ID) ENTIFICACION Y CUANTIFICA- CION CROMATOGRAFICA DE LOS OXIESTERO- LES.}

Para conseguir identificar los diferentes oxiesteroles es necesario un método con una buena resolución y buena sensibilidad. Estos dos requisitos son todavía más indispensables si, como es habitual, se quiere realizar la cuantificación. Esta cuantificación de los OE normalmente se realiza por CG o CLAE, aunque en algunas ocasiones se hace por CCF. La identificación mediante estas técnicas no debería considerarse definitiva y se debería comprobar por espectrometría de masas.

Recientemente, Fontana et al. (1992) cuantificó los OE por espectroscopía ${ }^{~} \mathrm{H}-\mathrm{RMN}$, tras la purificación exhaustiva de cada OE mediante una doble CLAE preparativa. 
Tabla II

Métodos en la identificación y/o cuantificación de OE

\begin{tabular}{|c|c|c|c|c|}
\hline $\begin{array}{c}\text { Referencia } \\
\text { bibliográfica }\end{array}$ & Muestra & Patrones de oxiesteroles & Extracción & Saponificación \\
\hline Addis et al., 1989. & $\begin{array}{l}\text { Lipoproteínas obtenidas de } \\
\text { plasma humano. }\end{array}$ & $\begin{array}{l}\alpha-\mathrm{CE}, \mathrm{B}-\mathrm{CE}, 7 \alpha-\mathrm{HC}, 7 \beta-\mathrm{HC}, \\
7-\mathrm{CC} \text { y } 5 \alpha-\mathrm{CL}^{\mathrm{a}}\end{array}$ & $\begin{array}{l}\text { CLO/MET } \quad(2: 1, \\
\mathrm{v} / \mathrm{v}) .\end{array}$ & $\begin{array}{l}\text { KOH metanólica } 1 \mathrm{~N} \\
\text { (en frío). }\end{array}$ \\
\hline $\begin{array}{l}\text { Bascoul et al., } \\
1986 .\end{array}$ & Sebos calentados. & $\begin{array}{l}\alpha-\mathrm{CE}, \beta-\mathrm{CE}, 7 \alpha-\mathrm{HC}, 7 \beta-\mathrm{HC}, \\
25-\mathrm{HC}, \mathrm{CT}, 7-\mathrm{CC}, 20 \alpha-\mathrm{HC}, \\
\text { colesta-3,5-dien-7-ona } \\
\text { colestenona }{ }^{\mathrm{a}} \text {. }\end{array}$ & - & $\begin{array}{l}\text { KOH metanólica 1N } \\
\text { (en caliente). }\end{array}$ \\
\hline $\begin{array}{l}\text { Cleveland y Harris, } \\
1987 .\end{array}$ & $\begin{array}{l}\text { e c h e : c o mplet a } \\
\text { (pasteurizada, UHT y } \\
\text { evaporada) y desnatada } \\
\text { (líquida y en polvo). }\end{array}$ & $\begin{array}{l}\alpha-\mathrm{CE}, \beta-\mathrm{CE}, 7 \alpha-\mathrm{HC}, 7 \beta-\mathrm{HC}, \\
\text { 25-HC, CT, 7-CC, } 20 \alpha-\mathrm{HC}, \\
\text { colest-4-en-3-ona y colesta- } \\
\text { 4,6-dien-3-ona. }\end{array}$ & $\begin{array}{l}\mathrm{HEX} / \mathrm{ISO} \quad(1: 2, \\
\mathrm{v} / \mathrm{v})\end{array}$ & - \\
\hline $\begin{array}{l}\text { Csallany et al., } \\
1989 .\end{array}$ & $\begin{array}{l}\text { carne de cerdo e higado de } \\
\text { rata: frescos, conservados } \\
\text { diferentes períodos bajo } \\
\text { diferentes condiciones } \\
\text { irradiados. }\end{array}$ & $\begin{array}{l}\alpha-\mathrm{CE}, \beta-\mathrm{CE}, 7 \alpha-\mathrm{HC}, 7 \beta-\mathrm{HC}, \\
25-\mathrm{HC} \text { y } 7-\mathrm{CC} \text {. Método de } \\
\text { cuantificación: patrón } \\
\text { externo. }\end{array}$ & $\begin{array}{l}\text { CLO/MET }(2: 1, \\
\mathrm{v} / \mathrm{v})\end{array}$ & - \\
\hline Csiky, 1982. & $\begin{array}{l}\text { Mantequilla sometida o no a } \\
\text { calentamiento. }\end{array}$ & $\begin{array}{l}7 \alpha-\mathrm{HC}, 7 \beta-\mathrm{HC}, 25-\mathrm{HC}, 7- \\
\mathrm{CC}, 20 \alpha-\mathrm{HC}, \quad 4 \beta-\mathrm{HC} . \\
\text { Método de cuantificación: } \\
\text { patrón externo. }\end{array}$ & - & - \\
\hline De Vore, 1988. & $\begin{array}{lr}\text { Estudio de almacenaje de } \\
\text { hamburguesas frescas y } \\
\text { cocidas con microondas. }\end{array}$ & $\begin{array}{l}7 \text { - C C. Método de } \\
\text { cuantificación: patrón } \\
\text { externo. }\end{array}$ & $\begin{array}{l}\text { CLO/MET } \quad(2: 1, \\
\mathrm{v} / \mathrm{v})\end{array}$ & \\
\hline $\begin{array}{l}\text { Emanuel et al., } \\
1991 .\end{array}$ & $\begin{array}{l}\text { Plasma y quilomicrones } \\
\text { plasmáticos. }\end{array}$ & $\begin{array}{l}\alpha-\mathrm{CE}, \beta-\mathrm{CE}, 7 \beta-\mathrm{HC}, 7-\mathrm{CC} \mathrm{y} \\
5 \alpha-\mathrm{CL}^{\mathrm{a}} \text {. }\end{array}$ & $\begin{array}{l}\text { CLO/MET }(2: 1, \\
\mathrm{v} / \mathrm{v}) .\end{array}$ & $\begin{array}{l}\text { KOH metanólica } 1 \mathrm{~N} \\
\text { (en frío). }\end{array}$ \\
\hline Fillion et al., 1991. & $\begin{array}{l}\text { Patrones por separado y como } \\
\text { mezclas. }\end{array}$ & $\begin{array}{l}\alpha-\mathrm{CE}, \beta-\mathrm{CE}, 7 \alpha-\mathrm{HC}, 7 \beta-\mathrm{HC}, \\
25-\mathrm{HC}, \mathrm{CT} \text { y } 7-\mathrm{CC} \text {. Método } \\
\text { de cuantificación: patrón } \\
\text { externo. }\end{array}$ & - & - \\
\hline
\end{tabular}

a Patrón interno. 
Tabla II

\section{Métodos en la identificación y/o cuantificación de OE}

\begin{tabular}{|c|c|c|c|c|}
\hline $\begin{array}{c}\text { Referencia } \\
\text { bilbliográfica }\end{array}$ & Purificación & Identificación & Cuantificación & $\begin{array}{l}\text { Oxiesteroles detectados } \\
\text { en las muestras }\end{array}$ \\
\hline Addis et al., 1989. & - & $\begin{array}{l}\text { CG: TR y CoC. } \\
\text { CG-EM. }\end{array}$ & $\begin{array}{l}\text { Derivatización (TMS) con } \\
\text { Sylon BTZ. } \\
\text { CG con CC DB-1 (de } 180^{\circ} \mathrm{C} \\
\left.\rightarrow 210^{\circ} \mathrm{C} \text { a } 3^{\circ} \mathrm{C} / \mathrm{min}\right) .\end{array}$ & $\begin{array}{l}\text { Cuantificados: } \alpha-\mathrm{CE}, \beta- \\
\mathrm{CE}, 7 \alpha-\mathrm{HC}, 7 \beta-\mathrm{HC}, 7- \\
\mathrm{CC} .\end{array}$ \\
\hline Bascoul et al. 1986. & - & $\begin{array}{l}\text { CCF con gel de } \\
\text { sílice: Rf. } \\
\text { CG: TR. } \\
\text { CG-EM. } \\
\end{array}$ & $\begin{array}{l}\text { Comparación de } 2 \text { métodos: } \\
\text {-CCF-DIL con gel de sílice; } \\
\text {-CG con CC SE-54 a } 274^{\circ} \mathrm{C} \\
\text { con derivatización de los OE } \\
\text { con grupo C }=0 \text { en forma de } \\
\text { metiloxima y en forma de } \\
\text { TMS para los que tienen } \\
\text { grupo -OH. }\end{array}$ & $\begin{array}{l}\text { Cuantificados: } 7 \alpha-\mathrm{HC} \\
\text { 7ß-HC y 7-CC. } \\
\text { Oservación: se da } \\
\text { separación de los } \\
\text { patrones ensayados. }\end{array}$ \\
\hline $\begin{array}{l}\text { Cleveland y Harris, } \\
1987 .\end{array}$ & $\begin{array}{l}\text { CCF preparativa con gel de } \\
\text { sílice. }\end{array}$ & $\begin{array}{l}\text { CCF con gel de } \\
\text { sílice: } R f . \\
\text { CG-EM }(70 \mathrm{ev}) .\end{array}$ & - & $\begin{array}{l}\text { Identificado: } 7-\mathrm{HC} \\
\text { (posiblemente } 7 \mathrm{~B}-\mathrm{HC} \text { ). }\end{array}$ \\
\hline Csallany, 1989. & - & $\begin{array}{l}\text { CLAE: TR y CoC. } \\
\text { CG-EM }(23 \mathrm{ev}) .\end{array}$ & $\begin{array}{l}\text { CLAE con columna de } \mu- \\
\text { Porasil: } \\
\text {-FM, HEX/ISO }(93: 7, \text { v/v) } \\
\text { para determinar } 7 \alpha-\mathrm{HC}, 7 \beta- \\
\text { HC y 7-CC y HEX/ISO } \\
(97: 3, \text { v/v) para determinar } \\
25-\mathrm{HC} \text {; } \\
\text {-detector, UV (233 nm para } \\
\text { 7-CC y } 206 \mathrm{~nm} \text { para el resto } \\
\text { de OE). }\end{array}$ & $\begin{array}{l}\text { Cuantificados: } 7 \alpha-\mathrm{HC}, \\
7 \beta-\mathrm{HC} \text { y } 7-\mathrm{CC} \text {. } \\
\text { Obsevaciones: método no } \\
\text { válido para determinar } \\
\alpha \text {-CE y } \beta-C E \text { ya que no } \\
\text { absorben al UV, se dan } \\
1 \text { a li n e a } 1 \text { i d a d, } \\
\text { recuperaciones, LC y los } \\
\text { espectros UV de los } \\
\text { patrones de OE. }\end{array}$ \\
\hline Csiky, 1982. & $\begin{array}{l}\text { CLAE preparativa con } \\
\text { columna Nucleosil } \mathrm{NO}_{2}: \\
\text {-FM, HEX; } \\
\text {-detector, UV }(210 \mathrm{~nm}) .\end{array}$ & CLAE: TR y CoC & $\begin{array}{l}\text { CLAE con columna de } \\
\text { Nucleosil } \mathrm{NO}_{2} \text { : } \\
\text {-FM, BUT en HEX } \\
\text { gradiente lineal }(0-10 \%) \text {; } \\
\text {-detector, UV }(206 \mathrm{~nm}) .\end{array}$ & $\begin{array}{l}\text { Cuantificados : } 7 \alpha-\mathrm{HC} \text {, } \\
7 \beta-H C, 25-\mathrm{HC}, 7-\mathrm{CC} \text { y } \\
4 \beta-H C \text {. } \\
\text { Observación: método no } \\
\text { válido para determinar } \\
20 \alpha-\mathrm{HC} \text {. }\end{array}$ \\
\hline De Vore, 1988. & \begin{tabular}{llll|}
$\begin{array}{l}\text { Minicolumna de } \\
\text { sílice. }\end{array}$ & & & \\
\end{tabular} & $\begin{array}{l}\text { CLAE: TR y CoC. } \\
\text { CG-EM }(70 \mathrm{ev}) .\end{array}$ & $\begin{array}{l}\text { CLAE con columna de gel } \\
\text { de sílice: } \\
\text {-FM, HEX/ISO }(93: 7, \mathrm{v} / \mathrm{v}) \text {; } \\
\text {-detector, UV }(233 \mathrm{~nm}) .\end{array}$ & $\begin{array}{l}\text { Cuantificado: } 7-\mathrm{CC} . \\
\text { Observación: se da } \\
\text { recuperación del método. }\end{array}$ \\
\hline $\begin{array}{l}\text { Emanuel et al. } \\
1991 .\end{array}$ & - & $\begin{array}{l}\text { CG: TR y CoC. } \\
\text { CG-EM }(70 \mathrm{ev}) .\end{array}$ & $\begin{array}{l}\text { Derivatización (TMS) con } \\
\text { Sylon BTZ. } \\
\text { CG con CC DB-1 (de } 180^{\circ} \mathrm{C} \\
\left.\rightarrow 210^{\circ} \mathrm{C} \text { a } 3^{\circ} \mathrm{C} / \mathrm{min}\right)\end{array}$ & $\begin{array}{l}\text { Cuantificados: } \alpha-C E, \beta- \\
\text { CE, } 7 \beta-H C \text { y } 7-C C \text {. }\end{array}$ \\
\hline Fillion et al., 1991. & - & Se dan TR y K'. & $\begin{array}{l}\text { Derivatización (benzoilación) } \\
\text { con CB. } \\
\text { CLAE fase reversa con } \\
\text { columna de Novapak } \mathrm{C}_{18} \text { : } \\
\text {-FM, ISO/agua }(85: 15, \mathrm{v} / \mathrm{v}) \text {; } \\
\text {-detector, UV }(230 \mathrm{~nm}) \text {. } \\
\text { La derivatización implica un } \\
\text { aumento de absorción a } 230 \\
\text { nm con lo cual aumenta la } \\
\text { sensibilidad del método y se } \\
\text { pueden detectar todos los } \\
\text { OE a la misma longitud de } \\
\text { onda }(230 \mathrm{~nm}) \text {. }\end{array}$ & $\begin{array}{l}\text { Se calcula la linealidad y } \\
\text { el LD del método para: } \\
\text { CE }(\alpha-C E+\beta-C E), 7-H C \\
(7 \alpha-H C+7 \beta-H C), 25- \\
\text { HC, CT y 7-CC. } \\
\text { Este método no separa } \\
\text { lo s is ó m eros d el } \\
\text { colesterol-5,6-epóxido y } \\
\text { del 7-hidroxicolesterol. }\end{array}$ \\
\hline
\end{tabular}


Tabla II

Métodos en la identificación y/o cuantificación de OE

\begin{tabular}{|c|c|c|c|c|}
\hline $\begin{array}{c}\text { Referencia } \\
\text { bibliográfica }\end{array}$ & Muestra & Patrones de oxiesteroles & Extracción & Saponificación \\
\hline $\begin{array}{l}\text { Finocchiaro et al., } \\
1984 .\end{array}$ & $\begin{array}{l}\text { Quesos y mantequilla fundida } \\
\text { clarificada (recién elaborada y } \\
\text { almacenada bajo diferentes } \\
\text { condicones). }\end{array}$ & $\begin{array}{l}\alpha-\mathrm{CE}, 7 \alpha-\mathrm{HC}, 7 \beta-\mathrm{HC} \text { y CT. } \\
\text { Método de cuantificación: } \\
\text { patrón externo. }\end{array}$ & $\begin{array}{l}\text { CLO/MET } \quad(2: 1, \\
\mathrm{v} / \mathrm{v})\end{array}$ & $\begin{array}{l}\text { KOH etanólica } 1.5 \mathrm{~N} \\
\text { (en caliente). }\end{array}$ \\
\hline $\begin{array}{l}\text { Fontana et al., } \\
1992 .\end{array}$ & $\begin{array}{l}\text { Yema de huevo en polvo } \\
\text { obtenida por atomización. }\end{array}$ & $\begin{array}{l}\alpha-\mathrm{CE}, \beta-\mathrm{CE}, 7 \alpha-\mathrm{HC}, 7 \beta-\mathrm{HC}, \\
25-\mathrm{HC}, \mathrm{CT}, 7-\mathrm{CC}, 20-\mathrm{HC} \\
\text { éster metílico del ácido } p- \\
\text { hidroxibenzoico }{ }^{\mathrm{a}} \text {. }\end{array}$ & $\begin{array}{l}\text { En columna de gel } \\
\text { de sílice. Elución } \\
\text { con fracciones de } \\
\text { polaridad creciente. }\end{array}$ & - \\
\hline \begin{tabular}{lll|} 
Herian y & Lee, \\
1985. & & \\
& & \\
\end{tabular} & $\begin{array}{l}\text { Estudio de irradiación de } \\
\text { huevo en polvo con luz } \\
\text { fluorescente. }\end{array}$ & $\begin{array}{l}7 \alpha-H C \text { y } 7 \beta-H C . \text { Método de } \\
\text { cuantificación: patrón } \\
\text { externo. }\end{array}$ & $\begin{array}{l}\text { CLO/MET } \quad(2: 1, \\
\mathrm{v} / \mathrm{v})\end{array}$ & $\begin{array}{l}\text { KOH etanólica } 1.5 \mathrm{~N} \\
\text { (en caliente). }\end{array}$ \\
\hline Higley et al., 1986. & $\begin{array}{l}\text { Carnes y productos cárnicos: } \\
\text { frescos y cocidos. }\end{array}$ & $\begin{array}{l}7 \alpha-\mathrm{HC}, 7 \mathrm{~B}-\mathrm{HC}, 25-\mathrm{HC}, \mathrm{CT} \\
7-\mathrm{CC}, 20 \alpha-\mathrm{HC}, 19-\mathrm{HC}, 22 \mathrm{~S}- \\
\mathrm{HC}, 22-\mathrm{CC} \text { y } 6-\mathrm{CC}\end{array}$ & $\begin{array}{l}\text { En columna de } \\
\text { Celita } 545+ \\
\mathrm{C} \text { a } \mathrm{H} \mathrm{PO}_{4} \cdot 2 \mathrm{H}_{2} \mathrm{O} \\
\text { Elución con cloruro } \\
\text { de metileno/MET } \\
(9: 1, \mathrm{v} / \mathrm{v}) .\end{array}$ & $\begin{array}{l}\text { KOH metanólica } \\
0.5 \mathrm{~N} \text { (en caliente). }\end{array}$ \\
\hline $\begin{array}{l}\text { Hwang y Maerker, } \\
1993 .\end{array}$ & $\begin{array}{l}\text { Estudio de conservación de } \\
\text { carnes de buey, ternera y } \\
\text { cerdo (irradiadas o no con } \\
\text { rayos gamma). }\end{array}$ & $\begin{array}{l}\text { Grupo 1: } \alpha \text {-CE, } \beta \text {-CE, 7-CC } \\
\text { y 7-CCL } \\
\text { Grupo } 2: \text { colest-4-en-3-ona, } \\
\text { colest-4-en-3,6-dion a, } \\
\text { colesta-4,6-dien-3-ona y } \\
\text { colesta-5,24-dien-3B-ol }{ }^{a} \\
\text { (desmosterol). }\end{array}$ & \begin{tabular}{|l|} 
CLO/MET \\
v/v).
\end{tabular} & \\
\hline Ibrahim et al. 1990. & $\begin{array}{l}\text { Mezcla de carne de cerdo con } \\
\text { un subproducto procedente de } \\
\text { la extracción de aceite de soja } \\
\text { (c a lenta a a varias } \\
\text { temperaturas durante períodos } \\
\text { de tiempo de diferente } \\
\text { duración). }\end{array}$ & $\begin{array}{l}\text { CE (no especifica cual de los } \\
\text { dos isómeros), 7ß-HC, CT, } \\
25-\mathrm{HC}, 7-\mathrm{CC} \text { y } 5 \alpha-\mathrm{CL}^{\mathrm{a}} \text {. }\end{array}$ & $\begin{array}{l}\text { CLO/MET } \quad(2: 1, \\
\mathrm{v} / \mathrm{v})\end{array}$ & $\begin{array}{l}\text { KOH metanólica } 2 \mathrm{~N} \\
\text { (en frío). }\end{array}$ \\
\hline Jacobson, 1987. & $\begin{array}{llr}\text { Mantequilla } & \text { y mantequilla } \\
\text { clarificada } & \text { (ghee) } & \text { recién } \\
\text { elaboradas. } & & \end{array}$ & $\begin{array}{l}\text { CE (no especifica cual de los } \\
\text { dos isómeros), } 7 \alpha-\mathrm{HC}, 7 \beta- \\
\mathrm{HC}, \mathrm{CT}, 25-\mathrm{HC} \text { y } 20 \alpha-\mathrm{HC}\end{array}$ & - & $\begin{array}{|lr|}\text { KOH } 15 \% & \text { (en } \\
\text { caliente y } & \text { en } \\
\text { a tmós fera } & \text { de } \\
\text { nitrógeno). } & \end{array}$ \\
\hline
\end{tabular}

\footnotetext{
${ }^{\text {a }}$ Patrón interno.
} 
Tabla II

Métodos en la identificación y/o cuantificación de OE

\begin{tabular}{|c|c|c|c|c|}
\hline $\begin{array}{c}\text { Referencia } \\
\text { bilbliográfica }\end{array}$ & Purificación & Identificación & Cuantificación & $\begin{array}{l}\text { Oxiesteroles detectados } \\
\text { en las muestras }\end{array}$ \\
\hline $\begin{array}{l}\text { Finocchiaro et al., } \\
1984 .\end{array}$ & $\begin{array}{l}\text { CCF preparativa con gel de } \\
\text { sílice. }\end{array}$ & $\begin{array}{l}\text { CCF con gel de } \\
\text { sílice: Rf. } \\
\text { CLAE: TR. } \\
\text { EM con los OE } \\
\text { p u r i f i a d o s } \\
\text { procedentes de } \\
\text { CLAE. }\end{array}$ & $\begin{array}{l}\text { D o s m é t o d o s d e } \\
\text { cuantificaciion: } \\
\text { CCF con gel de sílice. } \\
\text { CLAE fase reversa con } \\
\text { columna } \mu \text {-Bondapak } C_{18}: \\
\text {-FM, ACE/agua }(9: 1, \mathrm{v} / \mathrm{v}) \text {; } \\
\text {-detector, UV }(212 \mathrm{~nm}) \text { para } \\
\text { 7-HCs y refractómetro para } \\
\text { CT, } \alpha \text {-CE y } B-C E .\end{array}$ & $\begin{array}{l}\text { Cuantificados: CEs, } 7 \alpha- \\
\text { HC, } 7 \text {-HC y CT. } \\
\text { Observación: el método } \\
\text { separa los CEs pero se } \\
\text { dan juntos ya que sólo se } \\
\text { dispone de patrón de } \alpha- \\
\text { CE }\end{array}$ \\
\hline $\begin{array}{l}\text { Fontana, et al., } \\
1992 .\end{array}$ & 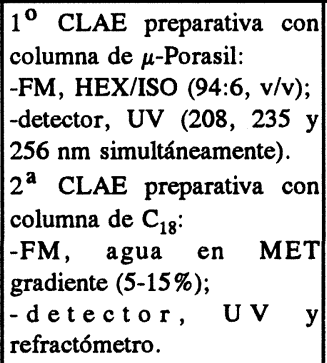 & $\begin{array}{l}\text { CCF con gel de } \\
\text { sílice: Rf. } \\
\text { CLAE: TR y CoC. } \\
{ }^{1} \text { H-RMN. }\end{array}$ & ${ }^{1} \mathrm{H}-\mathrm{RMN} 500 \mathrm{MHz}$. & $\begin{array}{l}\text { Cuantificados: } \alpha \text {-CE, } \beta- \\
\text { CE, } 7 \alpha-\mathrm{HC}, 7 \beta-\mathrm{HC} \text { y } 7- \\
\text { CC. } \\
\text { Observaciones: se dan } \\
1 \text { i n e a } 1 \text { i d a d y } \\
\text { r e c u p e r a c i o n e s } \\
\text { calculadas adicionando } \\
\text { patrones a yema de } \\
\text { huevo en polvo obtenida } \\
\text { por liofilización. }\end{array}$ \\
\hline \begin{tabular}{lll|} 
Herian & $y$ & Lee, \\
1985. & & \\
\end{tabular} & $\begin{array}{l}1^{\mathrm{o}} \text { columna de gel de sílice. } \\
2^{\mathrm{o}} \text { columna de Florisil- } \\
\mathrm{AgNO}_{3} .\end{array}$ & $\begin{array}{|ll|}\text { CCF con gel de } \\
\text { sílice: } R f .\end{array}$ & $\begin{array}{l}\text { CLAE con columna de } \\
\text { LiChrosorb Si 60: } \\
\text {-FM, HEX/ISO (100:3, v/v } \\
\text { y 11:1, v/v); } \\
\text {-detector, refractómetro. }\end{array}$ & $\begin{array}{l}\text { Cuantificados: } 7 \alpha-H C \text { y } \\
7 \beta-H C \text {. } \\
\text { Observación: inyectados } \\
\text { a igual concentración dan } \\
\text { picos con áreas iguales. }\end{array}$ \\
\hline Higley et al., 1986. & $\begin{array}{l}1^{\circ} \text { columna de gel de sílice. } \\
2^{\circ} \text { columna de Florisil- } \\
\mathrm{AgNO}_{3} \text {. } \\
3^{\circ} \text { cartucho de gel de súlice } \\
(\text { Sep-Pak) se recogen } 2 \\
\text { eluatos: } \mathrm{A} \text { y } \mathrm{B} \text {. B contiene el } \\
\text { CT y A el resto de OE. }\end{array}$ & $\begin{array}{l}\text { CCF con gel de } \\
\text { sílice: Rf. } \\
\text { CLAE: TR. } \\
\end{array}$ & $\begin{array}{l}\text { CLAE con columna de } \\
\text { Accupak Si del eluato A: } \\
\text {-FM, HEX/ISO }(96: 4, \mathrm{v} / \mathrm{v}) \text {; } \\
\text {-detector, UV }(212 \mathrm{~nm}) \text {. } \\
\text { CLAE fase reversa con } \\
\text { columna de microsorb C } 18 \\
\text { del eluato B: } \\
\text {-FM, ACE/agua }(9: 1, \mathrm{v} / \mathrm{v}) \text {. } \\
\text {-detector, UV }(240 \mathrm{~nm}) .\end{array}$ & $\begin{array}{l}\text { Cuantificados: } 7 \alpha-\mathrm{HC}, \\
\text { 7B-HC, CT, 19-HC, 22- } \\
\text { CC y 6-CC. }\end{array}$ \\
\hline $\begin{array}{l}\text { Hwang y Maerker, } \\
1993 .\end{array}$ & $\begin{array}{l}1^{\circ} \text { minicolumna de gel de } \\
\text { sílice. } \\
2^{\circ} \text { minicolumna de gel de } \\
\text { sílice. } \\
3^{\circ} \text { CCF con gel de sílice. } \\
\text { con estas tres fases se } \\
\text { separan los compuestos del } \\
\text { grupo } 1 \text { y del } 2 \text {. }\end{array}$ & \begin{tabular}{|l} 
CCF con gel de \\
sílice: Rf. \\
CG: TR. \\
\end{tabular} & $\begin{array}{l}\text { Sin derivatización. } \\
\text { CG (introducción de la } \\
\text { muestra en cabeza de } \\
\text { columna) con CC DB-5 (3 } \\
\text { min a } 100^{\circ} \mathrm{C} \text {, de } 100{ }^{\circ} \mathrm{C} \rightarrow \\
260^{\circ} \mathrm{C} \text { a } 30^{\circ} \mathrm{C} / \mathrm{min} \text {, de } 260 \\
{ }^{\circ} \mathrm{C} \rightarrow 277^{\circ} \mathrm{C} \text { a } 0.6^{\circ} \mathrm{C} / \mathrm{min} \text { y } \\
\text { de } 277^{\circ} \mathrm{C} \rightarrow 310^{\circ} \mathrm{C} \text { a } 30 \\
\left.{ }^{\circ} \mathrm{C}\right) .\end{array}$ & $\begin{array}{l}\text { Cuantificados: todos los } \\
\text { patrones de OE. } \\
\text { Observaciones: se dan } \\
\text { recuperaciones y LD. } \\
\end{array}$ \\
\hline Ibrahim et al. 1990. & Columna de alúmina. & $\begin{array}{l}\text { CG: TR y CoC. } \\
\text { CG-EM }\end{array}$ & $\begin{array}{l}\text { CG con CC DB-1 (de } 100 \\
\left.{ }^{\circ} \mathrm{C} \rightarrow 265^{\circ} \mathrm{C} \text { a } 5^{\circ} \mathrm{C} / \mathrm{min}\right) .\end{array}$ & 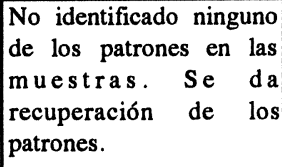 \\
\hline Jacobson, 1987. & & $\begin{array}{l}\text { CCF con gel de } \\
\text { sílice: Rf. } \\
\text { CLAE fase reversa } \\
\text { c o n c o l u m n a } \\
\text { Varian micropak } \\
\text { MCH10 C } 18 \text { : } \\
\text {-FM, MET; } \\
\text { - det e c to r, no } \\
\text { especificado. }\end{array}$ & $\begin{array}{l}\text { CCF-densitometría con gel } \\
\text { de sílice. }\end{array}$ & $\begin{array}{l}\text { Cuantificados: todos los } \\
\text { patrones de OE. }\end{array}$ \\
\hline
\end{tabular}


Tabla II

Métodos en la identificación y/o cuantificación de OE

\begin{tabular}{|c|c|c|c|c|}
\hline $\begin{array}{c}\text { Referencia } \\
\text { bibliográfica }\end{array}$ & Muestra & Patrones de oxiesteroles & Extracción & Saponificación \\
\hline $\begin{array}{l}\text { Korahani et al., } \\
1981 .\end{array}$ & $\begin{array}{l}\text { Patrones por separado y como } \\
\text { mezclas y colesterol } \\
\text { autooxidado por calefacción. }\end{array}$ & 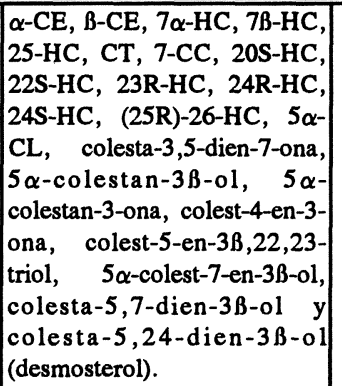 & $=$ & - \\
\hline Lee et al., 1985. & $\begin{array}{l}\text { Estudio de almacenaje de } \\
\text { patatas fritas y chips. }\end{array}$ & $\begin{array}{l}\alpha-C E, B-C E, 7 \alpha-H C, 7 B-H C, \\
25-H C, \quad C T, \quad 7-C C, \quad \alpha-S E, \\
7 \alpha-H S \text { y } 7 B-H S . \text { Método de } \\
\text { cuantificación: patrón } \\
\text { externo. }\end{array}$ & $\begin{array}{l}\text { CLO/MET (2:1, } \\
\mathrm{v} / \mathrm{v}) .\end{array}$ & $\begin{array}{l}\text { KOH etanólica } 1.5 \mathrm{~N} \\
\text { (en caliente). }\end{array}$ \\
\hline Luby et al., 1986. & $\begin{array}{l}\text { Estudio de irradiación de la } \\
\text { mantequilla con luz } \\
\text { fuorescente. }\end{array}$ & 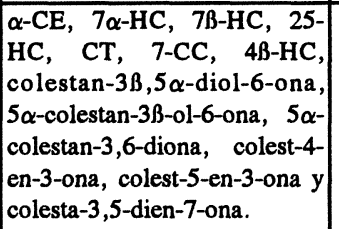 & - & $\begin{array}{l}\text { Según Itoh et al., } \\
1973 .\end{array}$ \\
\hline $\begin{array}{l}\text { Missler et al., } \\
1985 .,\end{array}$ & $\begin{array}{l}\text { Fórmulas en polvo a base de } \\
\text { huevo obtenidas por } \\
\text { atomización con fuente de } \\
\text { calor directa o indirecta. }\end{array}$ & $\begin{array}{l}\alpha-\mathrm{CE}, \beta-\mathrm{CE}, 7 \alpha-\mathrm{HC}, 7 \beta-\mathrm{HC}, \\
25-\mathrm{HC}, \mathrm{CT}, 7-\mathrm{CC}, 20 \alpha-\mathrm{HC} \\
\text { y 6-CCL }\end{array}$ & CLO. & - \\
\hline $\begin{array}{l}\text { M o r g a n } \\
\text { Armstrong, } 1987 .\end{array}$ & $\begin{array}{l}\text { Estudio de la obtención de } \\
\text { yema de huevo en polvo bajo } \\
\text { diferentes condiciones de } \\
\text { atomización con fuente de } \\
\text { calor indirecta. }\end{array}$ & $\begin{array}{l}\alpha-C E \text { M étodo de } \\
\text { cuantificación: patrón } \\
\text { externo. }\end{array}$ & $\begin{array}{l}\text { CLO/MET }(2: 1, \\
\mathrm{v} / \mathrm{v}) .\end{array}$ & \\
\hline $\begin{array}{l}\text { M o r g a n y } \\
\text { Armstrong, } 1989 .\end{array}$ & $\begin{array}{l}\text { Estudio de las recuperaciones } \\
\text { de diferentes patrones de OE } \\
\text { en yema de huevo en polvo. }\end{array}$ & $\begin{array}{l}\alpha-\mathrm{CE}, \beta-\mathrm{CE}, 7 \alpha-\mathrm{HC}, 7 \mathrm{~B}-\mathrm{HC}, \\
7-\mathrm{CC} \text { y } 3 \beta \text {-hidroxipregn-5-en- } \\
7,2 \text { 0 - d i o n a a }(7- \\
\text { cetopregnenolona). }\end{array}$ & $\begin{array}{l}\text { CLO/MET } \quad(2: 1, \\
\mathrm{v} / \mathrm{v})\end{array}$ & \\
\hline
\end{tabular}

${ }^{a}$ Patrón interno. 
Tabla II

Métodos en la identificación y/o cuantificación de OE

\begin{tabular}{|c|c|c|c|c|}
\hline $\begin{array}{c}\text { Referencia } \\
\text { bilbliográfica }\end{array}$ & Purificación & Identificación & Cuantificación & $\begin{array}{l}\text { Oxiesteroles } \\
\text { detectados. }\end{array}$ \\
\hline $\begin{array}{l}\text { Korahani et al., } \\
1981 .\end{array}$ & $\begin{array}{l}\text { CCF preparativa con gel de } \\
\text { sílice. }\end{array}$ & $\begin{array}{l}\text { CCF con gel de } \\
\text { sílice: } R f \text {. } \\
\text { CG-EM }(70 \mathrm{ev}) .\end{array}$ & $\begin{array}{l}\text { Derivatización (TMS) con } \\
\text { h ex a metildis il a za n o / } \\
\text { triclormetilsilano }(1: 1 \text {, v/v). } \\
\text { CG con CC OV-101 (285 } \\
\left.{ }^{\circ} \mathrm{C}\right) .\end{array}$ & $\begin{array}{l}\text { E n c o les t e r o } 1 \\
\text { a u t o o x i d a d o s e } \\
\text { cuantifican: } \alpha \text {-CE, } 7 \alpha- \\
\text { HC, 7B-HC, 25-HC, } 7- \\
\text { CC, 20S-HC, colesta- } \\
\text { 3,5-dien-7-ona. } \\
\text { Observaciones: se da } \\
\text { separación de los } \\
\text { patrones ensayados. }\end{array}$ \\
\hline Lee et al., 1985. & $\begin{array}{l}1^{\circ} \text { Columna de gel de sílice. } \\
2^{\circ} \text { Columna de Florisil- } \\
\mathrm{AgNO}_{3} .\end{array}$ & $\begin{array}{l}\text { CCF con gel de } \\
\text { sílice: } \text { Rf. } \\
\text { CLAE: TR. }\end{array}$ & $\begin{array}{l}\text { CLAE con columna de } \\
\text { LiChrosorb Si 60: } \\
\text {-FM, HEX/ISO (100:10, } \\
\text { v/v); } \\
\text {-detector, refractómetro. }\end{array}$ & $\begin{array}{l}\text { Cuantificados: } \alpha-\mathrm{CE}+\alpha- \\
\text { SE, } \beta-\mathrm{CE}, 7 \alpha-\mathrm{HC}+7 \alpha- \\
\text { HS, } 7 \beta-\mathrm{HC}+7 \beta H S \text {. } \\
\text { Observa ción: es te } \\
\text { método no separa los } \\
\text { derivados oxidados del } \\
\text { colesterol de los del } \beta- \\
\text { sitosterol. }\end{array}$ \\
\hline Luby et al., 1986. & & $\begin{array}{l}\text { CCF con gel de } \\
\text { sillice: Rf. } \\
\text { CG con CR } 3 \% \text { de } \\
\text { SP-2100 (260 }{ }^{\circ} \mathrm{C} \text {, } \\
\text { presenta poca } \\
\text { resolución): TR. }\end{array}$ & & $\begin{array}{l}\text { Identificados: } 7 \alpha-\mathrm{HC} \quad \mathrm{y} \\
7 \mathrm{~B}-\mathrm{HC} \text {. }\end{array}$ \\
\hline Missler et al. 1985. & $\begin{array}{l}1^{\circ} \text { columna de gel de sílice. } \\
2^{\circ} \text { CLAE preparativa con } \\
\text { columna de gel de sílice: } \\
\text {-FM, acetato de etilo. } \\
\text {-detector, refractómetro. }\end{array}$ & $\begin{array}{l}\text { CG: TR. } \\
\text { CG-EM (70 ev). }\end{array}$ & $\begin{array}{l}\text { Derivatización (TMS) con } \\
\text { BSTFA. } \\
\text { CG (introducción de la } \\
\text { muestra en cabeza de } \\
\text { columna) con CC DB-1 }(\text { de } \\
70^{\circ} \mathrm{C} \rightarrow 270^{\circ} \mathrm{C} \text { a } 25^{\circ} \mathrm{C} / \mathrm{min} \\
\text { y de } 270^{\circ} \mathrm{C} \rightarrow 300^{\circ} \mathrm{C} \text { a } 1 \\
\left.{ }^{\circ} \mathrm{C} / \mathrm{min}\right) .\end{array}$ & $\begin{array}{l}\text { Cuantificados: } \alpha-\mathrm{CE}, \beta- \\
\mathrm{CE}, 7 \alpha-\mathrm{HC}, 7 \beta-\mathrm{HC}, 25- \\
\mathrm{HC}, \mathrm{CT}, 7-\mathrm{CC} .\end{array}$ \\
\hline $\begin{array}{l}\text { M o r g a n y } \\
\text { Armstrong, } 1987 \text {. }\end{array}$ & $\begin{array}{l}\text { Cartucho de gel de súlice } \\
\text { (Sep-Pak). }\end{array}$ & CG: TR. & 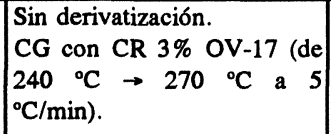 & $\begin{array}{l}\text { Cuantificados: } \alpha-C E+ \\
\beta-C E .\end{array}$ \\
\hline $\begin{array}{l}\text { M o r g a n y } \\
\text { Armstrong, } 1989 .\end{array}$ & $\begin{array}{l}\text { Cartucho de gel de sílice } \\
\text { (Sep-Pak). }\end{array}$ & CG: TR y CoC. & $\begin{array}{l}\text { Derivatización (TMS) con } \\
\text { BSTFA. } \\
\text { CG con CC HP-17 (de } 225 \\
\left.{ }^{\circ} \mathrm{C} \rightarrow 275^{\circ} \mathrm{C} \text { a } 1^{\circ} \mathrm{C} / \mathrm{min}\right)\end{array}$ & $\begin{array}{l}\text { S e calculan las } \\
\mathrm{r} \text { e c u p e r a c i o n e s } \\
\text { adicionando patrones a } \\
\text { yema de huevo en polvo } \\
\text { o b t e n i d a p o r } \\
\text { liofilización. Esta yema } \\
\text { sólo contiene pequeñas } \\
\text { cantidades de: 7 } \alpha \text {-HC, } \\
\text { 7ß-HC y 7-CC. }\end{array}$ \\
\hline
\end{tabular}


Tabla II

Métodos en la identificación y/o cuantificación de OE

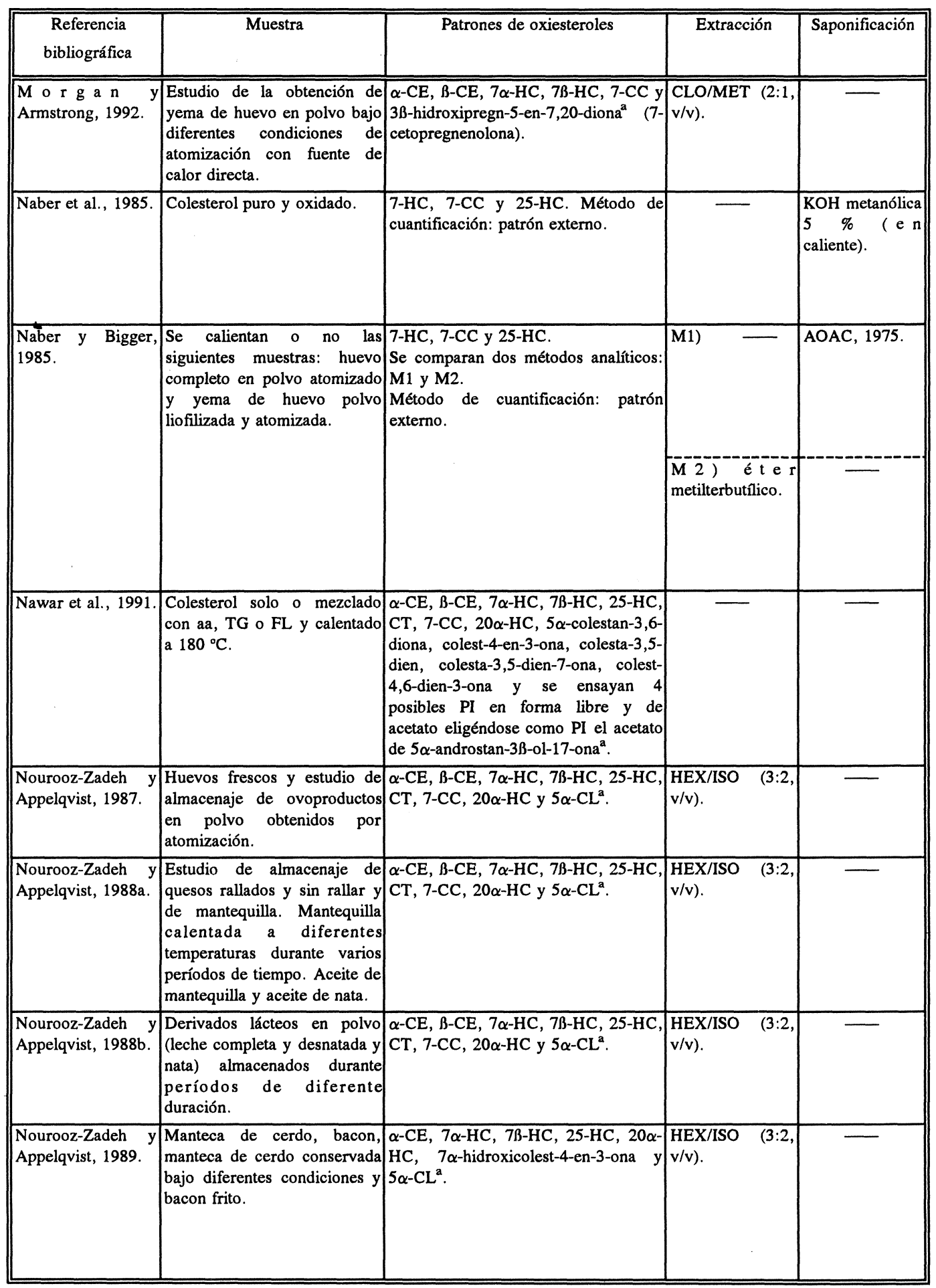

a Patrón interno. 
Tabla II

Métodos en la identificación y/o cuantificación de OE

\begin{tabular}{|c|c|c|c|c|}
\hline $\begin{array}{c}\text { Referencia } \\
\text { bilbliográfica }\end{array}$ & Purificación & Identificación & Cuantificación & $\begin{array}{l}\text { Oxiesteroles } \\
\text { detectados. }\end{array}$ \\
\hline $\begin{array}{l}\text { M o r g a n y } \\
\text { Armstrong, 1992. }\end{array}$ & $\begin{array}{l}\text { Cartucho de gel de sílice (Sep- } \\
\text { Pak). }\end{array}$ & CG: TR y CoC. & $\begin{array}{l}\text { Derivatización (TMS) con } \\
\text { BSTFA. } \\
\text { CG con CC HP-17 (de } 225 \\
{ }^{\circ} \mathrm{C} \rightarrow 275^{\circ} \mathrm{C} \text { a } 1^{\circ} \mathrm{C} / \mathrm{min} \text { ). }\end{array}$ & $\begin{array}{l}\text { Cuantificados: } \alpha \text {-CE, } \beta- \\
\text { CE, } 7 \alpha \text {-HC, } 7 \beta-H C \text { y } 7- \\
\text { CC. }\end{array}$ \\
\hline Naber et al. 1985 . & - & $\begin{array}{l}\text { CLAE: TR y } \\
\text { CoC. }\end{array}$ & $\begin{array}{l}\text { CLAE fase reversa con } \\
\text { columna de LiChrosorb RP } \\
\text { 18: } \\
\text {-FM, ACE/ISO/agua }(4: 5: 1, \\
\text { v/v/v); } \\
\text {-detector, UV }(208 \mathrm{~nm}) .\end{array}$ & $\begin{array}{l}\text { Cuantificados en } \\
\text { colesterol oxidado: } 7- \\
\text { HC, 25-HC y 7-CC. El } \\
\text { método no separa los } \\
\text { isómeros del 7-HC. }\end{array}$ \\
\hline \multirow[t]{2}{*}{$\begin{array}{l}\text { Naber y Bigger, } \\
1985 .\end{array}$} & - & $\begin{array}{l}\text { CLAE: TR y } \\
\text { CoC. }\end{array}$ & $\begin{array}{l}\text { CLAE fase reversa con } \\
\text { columna de LiChrosorb RP } \\
18: \\
-\mathrm{FM}, \text { ACE/ISO/agua }(4: 5: 1, \\
\mathrm{v} / \mathrm{v} / \mathrm{v}) ; \\
\text {-detector, UV }(208 \mathrm{~nm}) .\end{array}$ & $\begin{array}{l}\text { Cuantificados: } 25-\mathrm{HC} \text { y } \\
\text { 7-HC. } \\
\text { Observaciones: se dan } \\
\text { LD para el método que } \\
\text { no separa los isómeros } \\
\text { del 7-HC. }\end{array}$ \\
\hline & Columna de Biosil HA. & $\begin{array}{l}\text { CLAE: TR y } \\
\text { CoC. }\end{array}$ & $\begin{array}{l}\text { CLAE con columna de } \\
\text { LiChrosorb SI 60: } \\
\text {-FM, gradiente de éter } \\
\text { metilterbutílico/hexano; } \\
\text {-detector, UV (208 nm). }\end{array}$ & $\begin{array}{l}\text { Cuantificados: } 25-\mathrm{HC} \text { y } \\
\text { 7-CC. } \\
\text { Observaciones: se dan } \\
\text { LD para el método que } \\
\text { no separa los isómeros } \\
\text { del 7-HC. }\end{array}$ \\
\hline Nawar et al., 1991. & Minicolumna de gel de sílice. & $\begin{array}{l}\text { CG: TR. } \\
\text { CG-EM. }\end{array}$ & $\begin{array}{l}\text { Derivatización (TMS): } \\
\text { se ensayan varios reactivos } \\
\text { silanizantes y varias } \\
\text { condiciones de reacción. } \\
\text { CG con CC DB-1 o Ultra- } 1 \\
\left({ }^{*} \text { de } 100^{\circ} \mathrm{C} \rightarrow 300^{\circ} \mathrm{C} \text { a } 10\right. \\
\left.{ }^{\circ} \mathrm{C} / \mathrm{min} \sigma^{*} 295^{\circ} \mathrm{C}\right)\end{array}$ & $\begin{array}{l}\text { Cuantificados: } \alpha \text {-CE, } \beta- \\
\text { CE, } 7 \alpha-\mathrm{HC}, 7 \beta-\mathrm{HC}, 7- \\
\text { CC y colesta-3,5-dien-7- } \\
\text { ona. } \\
\text { Observación: se dan } \\
\text { FRR. }\end{array}$ \\
\hline \begin{tabular}{|l|} 
Nourooz-Zadeh \\
Appelqvist, 1987.
\end{tabular} & $\begin{array}{l}1^{\circ} \text { columna de Lipidex- } 5000 . \\
2^{\circ} \text { columna de TEAP-Lipidex. } \\
3^{\circ} \text { saponificación con } \mathrm{NaOH} \\
\text { etanólica } 2 \mathrm{~N} \text { (en caliente). }\end{array}$ & $\begin{array}{l}\text { CCF con gel de } \\
\text { sílice: } R f . \\
\text { CG: TR. } \\
\text { CG-EM }(40 \mathrm{ev}) .\end{array}$ & $\begin{array}{l}\text { Derivatización (TMS) con } \\
\text { Tri-Sil. } \\
\text { CG con CC de metil silicona } \\
\left(280^{\circ} \mathrm{C}\right) \text {. }\end{array}$ & $\begin{array}{l}\text { Cuantificados: todos los } \\
\text { patrones de OE. } \\
\text { Observación: se dan LD. }\end{array}$ \\
\hline $\begin{array}{l}\text { Nourooz-Zadeh y } \\
\text { Appelqvist, 1988a. }\end{array}$ & $\begin{array}{l}1^{\circ} \text { cartucho de gel de sílice } \\
\text { (Sep-Pak). } \\
2^{\circ} \text { columna de Lipidex-5000. } \\
3^{\circ} \text { columna de TEAP-Lipidex. } \\
4^{\circ} \text { saponificación con } \mathrm{NaOH} \\
\text { etanólica } 2 \mathrm{~N} \text { (en caliente). }\end{array}$ & $\begin{array}{l}\text { CG: TR. } \\
\text { CG-EM (40 ev). }\end{array}$ & $\begin{array}{l}\text { Derivatización (TMS) con } \\
\text { Tri-Sil. } \\
\text { CG con CC de metil silicona } \\
\left(258^{\circ} \mathrm{C}\right) \text {. }\end{array}$ & $\begin{array}{l}\text { Cuantificados: todos los } \\
\text { patrones de OE. } \\
\text { Observación: se dan LD. }\end{array}$ \\
\hline $\begin{array}{l}\text { Nourooz-Zadeh y } \\
\text { Appelqvist, 1988b. }\end{array}$ & $\begin{array}{l}1^{\circ} \text { cartucho de gel de sílice } \\
\text { (Sep-Pak). } \\
2^{\circ} \text { columna de TEAP-Lipidex. } \\
3^{\mathrm{o}} \text { saponificación con } \mathrm{NaOH} \\
\text { etanólica } 2 \mathrm{~N} \text { (en caliente). }\end{array}$ & $\begin{array}{l}\text { CCF con gel de } \\
\text { sílice: Rf. } \\
\text { CG: TR. } \\
\text { CG-EM }(40 \mathrm{ev}) .\end{array}$ & $\begin{array}{l}\text { Derivatización (TMS) con } \\
\text { Tri-Sil. } \\
\text { CG con CC de metil silicona } \\
\left(270^{\circ} \mathrm{C}\right) \text {. }\end{array}$ & $\begin{array}{l}\text { Cuantificados: todos los } \\
\text { patrones de OE. } \\
\text { Observación: se dan LD. }\end{array}$ \\
\hline $\begin{array}{l}\text { Nourooz-Zadeh y } \\
\text { Appelqvist, } 1989 .\end{array}$ & $\begin{array}{l}1^{\circ} \text { cartucho de gel de sílice } \\
(\text { Sep-Pak). } \\
2^{\circ} \text { columna de Lipidex-5000. } \\
3^{\circ} \text { columna de TEAP-Lipidex. } \\
4^{\circ} \text { saponificación con } \mathrm{NaOH} \\
\text { etanólica } 2 \mathrm{~N} \text { (en caliente). }\end{array}$ & $\begin{array}{l}\text { CCF con gel de } \\
\text { sílice: Rf. } \\
\text { CG: TR. } \\
\text { CG-EM }(40 \mathrm{ev}) . \\
\end{array}$ & $\begin{array}{l}\text { Derivatización (TMS) con } \\
\text { Tri-Sil. } \\
\text { CG con CC de metil silicona } \\
\left(270^{\circ} \mathrm{C}\right)\end{array}$ & $\begin{array}{l}\text { Cuantificados: } \alpha \text {-CE, } \\
7 \alpha \text {-HC, } 7 \beta-H C, 25-\mathrm{HC} \text { y } \\
20 \alpha \text {-HC. } \\
\text { O b s e r v a c i ó n : s e } \\
\text { identifica el } 7 \alpha- \\
\text { hidroxicolest-4-en-3-ona } \\
\text { por CG-EM. }\end{array}$ \\
\hline
\end{tabular}

* Inicio programa de temperatura de horno. 
Tabla II

Métodos en la identificación y/o cuantificación de OE

\begin{tabular}{|c|c|c|c|c|}
\hline $\begin{array}{c}\text { Referencia } \\
\text { bibliográfica }\end{array}$ & Muestra & Patrones de oxiesteroles & Extracción & Saponificación \\
\hline $\begin{array}{l}\text { Park y Addis, } \\
\text { 1985a. }\end{array}$ & $\begin{array}{l}\text { Patrones por separado o como } \\
\text { mezclas. }\end{array}$ & $\begin{array}{l}\alpha-\mathrm{CE}, 7 \alpha-\mathrm{HC}, 7 \mathrm{H}-\mathrm{HC}, 25- \\
\mathrm{HC}, \mathrm{CT}, 7-\mathrm{CC}, 4 \beta-\mathrm{HC}, 6- \\
\mathrm{CCL}, \text { colesta-3,5-dien-7-ona } \\
\text { y } 5 \alpha-\mathrm{CL}^{\mathrm{a}} .\end{array}$ & - & - \\
\hline $\begin{array}{l}\text { Park y Addis, } \\
\text { 1985b. }\end{array}$ & $\begin{array}{l}\text { Patatas fritas; pollo frito; } \\
\text { concentrados de cerebro e } \\
\text { hígado; carne, hígado y } \\
\text { cerebro de buey; etc. }\end{array}$ & $\begin{array}{l}7 \alpha-\mathrm{HC}, 7 \mathrm{~B}-\mathrm{HC}, 25-\mathrm{HC}, \mathrm{CT}, \\
7-\mathrm{CC} \text { y } 3 \text {-hidroxipregn-5-en- } \\
7,20-\mathrm{d} \text { i o n a }{ }^{\mathrm{a}} \quad(7- \\
\text { cetopregnenolona). }\end{array}$ & $\begin{array}{l}\text { CLO/MET } \\
\mathrm{v} / \mathrm{v})\end{array}$ & - \\
\hline $\begin{array}{l}\text { Park y Addis, } \\
\text { 1986a. }\end{array}$ & $\begin{array}{l}\text { Sebo de buey calentado a } \\
\text { diferentes temperaturas. }\end{array}$ & $\begin{array}{l}\alpha-\mathrm{CE}, \beta-\mathrm{CE}, 7 \alpha-\mathrm{HC}, 7 \mathrm{~B}-\mathrm{HC} \\
\mathrm{CT}, 7-\mathrm{CC} \text { y } 5 \alpha-\mathrm{CL}^{\mathrm{a}} .\end{array}$ & - & $\begin{array}{l}\text { KOH metanólica } 2 \mathrm{~N} \\
\text { (en frío). }\end{array}$ \\
\hline $\begin{array}{ll}\text { Park y Addis, } \\
\text { 1986b. }\end{array}$ & $\begin{array}{l}\text { Sebo calentado a diferentes } \\
\text { temperaturas. }\end{array}$ & $\alpha-\mathrm{CE}, 7-\mathrm{CC}$ y $5 \alpha-\mathrm{CL}^{2}$ & $=$ & $\begin{array}{l}\text { KOH metanólica } 1 \mathrm{~N} \\
\text { (en frío). }\end{array}$ \\
\hline $\begin{array}{ll}\text { Park y Addis, } \\
1987 .\end{array}$ & $\begin{array}{l}\text { Carnes (buey, cerdo y pavo) } \\
\text { cocinadas y precocinadas. } \\
\text { Carne de cerdo liofilizada } \\
\text { almacenada durante tres años. }\end{array}$ & $\begin{array}{l}\alpha-\mathrm{CE}, 7 \alpha-\mathrm{HC}, 7 \mathrm{~B}-\mathrm{HC}, \mathrm{CT} \\
7-\mathrm{CC} \text { y } 5 \alpha-\mathrm{CL}^{\mathrm{a}}\end{array}$ & $\begin{array}{l}\text { CLO/MET } \quad(2: 1, \\
\text { v/v). }\end{array}$ & $\begin{array}{l}\text { KOH metanólica } 2 \mathrm{~N} \\
\text { (en frío). }\end{array}$ \\
\hline Pie et al., 1990. & $\begin{array}{l}\text { Mantequilla calentada a } \\
\text { diferentes temperaturas y } \\
\text { almacenada durante períodos } \\
\text { de diferente duración. } \\
\text { Galletas de mantequilla y } \\
\text { ovoproductos. }\end{array}$ & $\begin{array}{l}\alpha-\mathrm{CE}, \beta-\mathrm{CE}, 7 \alpha-\mathrm{HC}, 7 \beta-\mathrm{HC} \\
25-\mathrm{HC}, \mathrm{CT}, 7-\mathrm{CC}, 20-\mathrm{HC} \\
26 \mathrm{R}-\mathrm{HC}, 26 \mathrm{~S}-\mathrm{HC} \text { y } 19-\mathrm{HC}^{\mathrm{a}}\end{array}$ & \begin{tabular}{|l} 
Etanol $\quad(0.002 \%$ \\
BHT $) /$ diclorometano \\
$(1: 1$, v/v). Para la \\
mantequilla s e \\
aplica directamente \\
la saponificación.
\end{tabular} & $\begin{array}{l}\text { KOH metanólica } 1 \mathrm{~N} \\
\text { (en frío). }\end{array}$ \\
\hline Pie et al., 1991. & \begin{tabular}{lccc|} 
Carnes & (Buey, ternera & y \\
cerdo) frescas, cocidas & o \\
almacenadas. & &
\end{tabular} & $\begin{array}{l}\alpha-\mathrm{CE}, \beta-\mathrm{CE}, 7 \alpha-\mathrm{HC}, 7 \beta-\mathrm{HC} \\
25-\mathrm{HC}, \mathrm{CT}, 7-\mathrm{CC} \text { y } 19-\mathrm{HC}^{\mathrm{a}}\end{array}$ & $\begin{array}{l}\text { CLO/MET (2:1, } \\
\text { v/v) con } 0.002 \% \mathrm{de} \\
\mathrm{BHT} \text {. }\end{array}$ & $\begin{array}{l}\text { KOH metanólica } 1 \mathrm{~N} \\
\text { (en frío). }\end{array}$ \\
\hline Pie y Seillan, 1992. & $\begin{array}{l}\text { Aortas de bóvidos, células } \\
\text { musculares de tejido liso } \\
\text { bovino y monocitos de la } \\
\text { línea U937. }\end{array}$ & $\begin{array}{l}\alpha-\mathrm{CE}, \beta-\mathrm{CE}, 7 \alpha-\mathrm{HC}, 7 \beta-\mathrm{HC} \\
25-\mathrm{HC}, \mathrm{CT}, 7-\mathrm{CC} \text { y } 19-\mathrm{HC}^{\mathrm{a}}\end{array}$ & \begin{tabular}{|l|} 
CLO/MET $\quad(2: 1$ \\
v/v) con $0.002 \% \mathrm{de}$ \\
BHT.
\end{tabular} & $\begin{array}{l}\text { KOH metanólica } 1 \mathrm{~N} \\
\text { (en frío). }\end{array}$ \\
\hline
\end{tabular}

${ }^{a}$ Patrón interno. 
Tabla II

Métodos en la identificación y/o cuantificación de OE

\begin{tabular}{|c|c|c|c|c|}
\hline $\begin{array}{c}\text { Referencia } \\
\text { bilbliográfica }\end{array}$ & Purificación & Identificación & Cuantificación & $\begin{array}{l}\text { Oxiesteroles } \\
\text { detectados. }\end{array}$ \\
\hline $\begin{array}{lll}\text { Park } & \text { y } & \text { Addis, } \\
\text { 1985a. } & \end{array}$ & - & $\begin{array}{l}\text { CG: TR. } \\
\text { CG-EM de los } \\
\text { patrones silanizados } \\
(70 \mathrm{ev}) .\end{array}$ & $\begin{array}{l}\text { Con o sin derivatización (TMS) } \\
\text { Sylon BTZ. } \\
\text { CG con CC. Estudio del } \\
\text { comportamiento de los patrones } \\
\text { ante tres fases estacionarias a } \\
\text { diferentes condiciones: DB-1 (* de } \\
200^{\circ} \mathrm{C} \rightarrow 260^{\circ} \mathrm{C} \text { a } 3^{\circ} \mathrm{C} / \mathrm{min} \text { y de } \\
\left.180^{\circ} \mathrm{C} \rightarrow 250^{\circ} \mathrm{C} \text { a } 3^{\circ} \mathrm{C} / \mathrm{min}\right) ; \mathrm{DB}-5 \\
\left(* \text { de } 220^{\circ} \mathrm{C} \rightarrow 260^{\circ} \mathrm{C} \text { a } 4^{\circ} \mathrm{C} / \mathrm{min} \text { y }\right. \\
*_{\left.\text {de } 230{ }^{\circ} \mathrm{C} \rightarrow 260^{\circ} \mathrm{C} \text { a } 2^{\circ} \mathrm{C} / \mathrm{min}\right) ;} \\
\text { y DB-1701 }\left(260^{\circ} \mathrm{C}\right)\end{array}$ & $\begin{array}{l}\text { Se da separación de los } \\
\text { patrones bajo las } \\
\text { diferentes condiciones } \\
\text { ensayadas. Se dan los } \\
\text { FRR y la linealidad. }\end{array}$ \\
\hline $\begin{array}{lll}\text { Park y } & \text { Addis, } \\
\text { 1985b. } & \end{array}$ & $\begin{array}{l}\text { Minicolumna de gel } \\
\text { de sillice. }\end{array}$ & $\begin{array}{l}\text { CLAE: TR y CoC. } \\
\text { CG-EM }(20 \mathrm{ev}) .\end{array}$ & $\begin{array}{l}\text { CLAE con columna de } \mu \text {-Porasil: } \\
\text {-FM, HEX/ISO }(93: 7, \mathrm{v} / \mathrm{v}) \text {; } \\
\text {-detector, UV (208 nm para el } 7 \alpha- \\
\text { HC y } 7 \text {-HC y } 233 \mathrm{~nm} \text { para el } 7- \\
\text { CC). }\end{array}$ & $\begin{array}{l}\text { Cuantificados: } 7 \alpha-\mathrm{HC} \text {, } \\
\text { 7ß-HC y } 7-\mathrm{CC} . \\
\text { Observaciones: se dan } \\
\text { FRR, linealidad y } \\
\text { recuperaciones. Método } \\
\text { no válido pa r a } \\
\text { cuantificar 25-HC y } \\
\text { CT. }\end{array}$ \\
\hline $\begin{array}{lll}\text { Park y } & \text { Addis, } \\
\text { 1986a. } & \\
& & \\
& \end{array}$ & - & $\begin{array}{l}\text { CG: TR y CoC. } \\
\text { CG-EM }(70 \mathrm{ev})\end{array}$ & $\begin{array}{l}\text { Con derivatización (TMS) con } \\
\text { Sylon BTZ. } \\
\text { CG con CC DB-1 (de } 180{ }^{\circ} \mathrm{C} \rightarrow \\
\left.250^{\circ} \mathrm{C} \text { a } 3^{\circ} \mathrm{C} / \mathrm{min}\right)\end{array}$ & $\begin{array}{l}\text { Cuantificados: todos los } \\
\text { patrones de OE. } \\
\text { Observaciones: se dan } \\
\text { p r e c i s i ó n } y \\
\text { recuperaciones del } \\
\text { método. }\end{array}$ \\
\hline $\begin{array}{lll}\text { Park y } & \text { Addis, } \\
\text { 1986b. } & \end{array}$ & - & $\begin{array}{l}\text { CG: TR y CoC. } \\
\text { CG-EM }(70 \mathrm{ev})\end{array}$ & $\begin{array}{l}\text { CG con CC según Park y Addis, } \\
1985 a \text {. }\end{array}$ & $\begin{array}{l}\text { Cuantificados: } \alpha \text {-CE y } \\
\text { 7-CC. }\end{array}$ \\
\hline \begin{tabular}{lll|} 
Park & y & Addis, \\
1987. & & \\
\end{tabular} & & $\begin{array}{l}\text { CG: TR y CoC. } \\
\text { CG-EM }(70 \mathrm{ev})\end{array}$ & $\begin{array}{l}\text { Con derivatización (TMS) con } \\
\text { Sylon BTZ. } \\
\text { CG con CC DB-1 (de } 180{ }^{\circ} \mathrm{C} \rightarrow \\
\left.250^{\circ} \mathrm{C} \text { a } 3^{\circ} \mathrm{C} / \mathrm{min}\right)\end{array}$ & $\begin{array}{l}\text { Cuantificados: todos los } \\
\text { patrones de OE. }\end{array}$ \\
\hline Pie et al., 1990. & $\begin{array}{l}\text { CCF preparativa con } \\
\text { gel de sílice. }\end{array}$ & $\begin{array}{l}\text { CG: TR. } \\
\text { CG-EM }(70 \mathrm{ev})\end{array}$ & $\begin{array}{l}\text { Con derivatización (TMS) con } \\
\mathrm{h} \text { e } \mathrm{x} \text { a } \mathrm{m} \text { e } \mathrm{t} \text { i } 1 \mathrm{~d} \text { is i } 1 \text { a } \mathrm{z} \text { a } \mathrm{n} \text { o } / \\
\text { triclorometilsilano }(1: 1, \mathrm{v} / \mathrm{v}) \\
\text { CG con CC DB-5 }\left(280^{\circ} \mathrm{C}\right)\end{array}$ & $\begin{array}{l}\text { Cuantificados: } \alpha-\mathrm{CE}, \\
\beta-\mathrm{CE}, 7 \alpha-\mathrm{HC}, 7 \beta-\mathrm{HC}, \\
25-\mathrm{HC}, \mathrm{CT}, 7-\mathrm{CC} \text { y } \\
\text { 20-HC. } \\
\text { Observaciones: se dan } \\
\text { FR , linealidad, } \\
\text { recuperaciones y LD. }\end{array}$ \\
\hline Pie et al., 1991. & $\begin{array}{l}\text { CCF preparativa con } \\
\text { gel de sillice. }\end{array}$ & $\begin{array}{l}\text { CG: TR. } \\
\text { CG-EM }(70 \mathrm{ev})\end{array}$ & $\begin{array}{l}\text { Con derivatización (TMS) con } \\
\mathrm{h} \text { e } \mathrm{x} \text { a } \mathrm{m} \text { e } \mathrm{t} \text { i } 1 \mathrm{~d} \text { i s i } 1 \text { a } \mathrm{z} \text { a } \mathrm{n} \text { o } \\
\text { triclorometilsilano }(1: 1, \mathrm{v} / \mathrm{v}) \text {. } \\
\text { CG con CC DB-5 }\left(280^{\circ} \mathrm{C}\right) \text {. }\end{array}$ & $\begin{array}{l}\text { Cuantificados: todos } \\
\text { los patrones de OE. }\end{array}$ \\
\hline Pie y Seillon, 1992. & $\begin{array}{l}\text { CCF preparativa con } \\
\text { gel de sílice. }\end{array}$ & CG: TR. & $\begin{array}{l}\text { Con derivatización (TMS) con } \\
\text { h e } \mathrm{x} \text { a m e } \mathrm{t} \text { i } 1 \mathrm{~d} \text { i s i } 1 \text { a } \mathrm{z} \text { a n o / } \\
\text { triclorometilsilano }(1: 1, \mathrm{v} / \mathrm{v}) \text {. } \\
\text { CG con CC DB-5 }\left(280^{\circ} \mathrm{C}\right) \text {. }\end{array}$ & $\begin{array}{l}\text { Cuantificados: todos } \\
\text { los patrones de OE. }\end{array}$ \\
\hline
\end{tabular}

* Inicio programa de temperatura de horno. 
Tabla II

Métodos en la identificación y/o cuantificación de OE

\begin{tabular}{|c|c|c|c|c|}
\hline $\begin{array}{c}\text { Referencia } \\
\text { bibliográfica }\end{array}$ & Muestra & Patrones de oxiesteroles & Extracción & Saponificación \\
\hline $\begin{array}{l}\text { P r a s a d y } \\
\text { Subramanian, } 1992 .\end{array}$ & $\begin{array}{l}\text { Mantequilla clarificada } \\
\text { (ghee). }\end{array}$ & CE y CT & - & $\begin{array}{ll}\text { KOH } 15 \% & \text { (en } \\
\text { caliente y } & \text { en } \\
\text { atmósfera } & \text { de } \\
\text { nitrógeno). } & \end{array}$ \\
\hline Sander et al. 1988. & $\begin{array}{l}\text { Estudio de la formación de } \\
\text { OE durante la elaboración y } \\
\text { almacenaje de la matequilla y } \\
\text { el queso Cheddar. }\end{array}$ & $\begin{array}{l}\alpha-\mathrm{CE}, \beta-\mathrm{CE}, 7 \alpha-\mathrm{HC}, 7 \mathrm{~B}-\mathrm{HC}, 25- \\
\mathrm{HC}, \mathrm{CT}, 7-\mathrm{CC} \text { y } 5 \alpha-\mathrm{CL}^{\mathrm{a}}\end{array}$ & $\begin{array}{l}\text { CLO/MET } \quad(2: 1, \\
\mathrm{v} / \mathrm{v}) .\end{array}$ & $\begin{array}{l}\text { KOH metanólica } \\
\text { IN (en frío). }\end{array}$ \\
\hline Sander et al. 1989. & $\begin{array}{l}\text { Estudio de almacenaje de } \\
\text { derivados lácteos en polvo. } \\
\text { Aceite de mantequilla } \\
\text { calentado a } 110^{\circ} \mathrm{C} \text { durante } \\
\text { diferentes períodos de tiempo. }\end{array}$ & $\begin{array}{l}\alpha-\mathrm{CE}, \mathrm{B}-\mathrm{CE}, 7 \alpha-\mathrm{HC}, 7 \mathrm{~B}-\mathrm{HC}, 25- \\
\mathrm{HC}, \mathrm{CT}, 7-\mathrm{CC} \text { y } 5 \alpha-\mathrm{CL}^{\mathrm{a}}\end{array}$ & $\begin{array}{l}\text { CLO/MET (2:1, } \\
\mathrm{v} / \mathrm{v}) \text {. En el caso del } \\
\text { a c e i t e r d e } \\
\text { mantequilla } \text { se } \\
\text { aplica directamente } \\
\text { la saponificación. }\end{array}$ & $\begin{array}{l}\text { KOH metanólica } \\
1 \mathrm{~N} \text { (en frío). }\end{array}$ \\
\hline Teng, 1990. & $\begin{array}{l}\text { Patrones por separado y como } \\
\text { mezclas. }\end{array}$ & 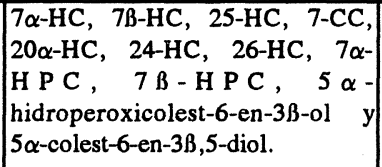 & $=$ & - \\
\hline Teng, 1991. & $\begin{array}{l}\text { Patrones por separado y como } \\
\text { mezclas. }\end{array}$ & 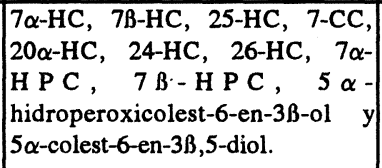 & $=$ & - \\
\hline Teng et al., 1973. & $\begin{array}{l}\text { Patrones por separado y como } \\
\text { mezclas. }\end{array}$ & $\begin{array}{l}7 \alpha-\mathrm{HC}, 7 \beta-\mathrm{HC}, 7-\mathrm{CC}, 7 \alpha-\mathrm{HPC}, \\
7 \beta-\mathrm{HPC}, 5 \alpha \text {-hidroperoxicolest-6- } \\
\text { en-3B-ol, } 5 \alpha \text {-colest-6-en-3B,5- } \\
\text { diol, colesta-3,5-dien-7-ona, } \\
\text { colesta-4,6-dien-3-ona y colest- } \\
\text { 2,4,6-trieno. }\end{array}$ & - & - \\
\hline $\begin{array}{ll}\text { Tsai y } & \text { Hudson, } \\
\text { 1981. } & \end{array}$ & $\begin{array}{l}\text { Patrones por separado y como } \\
\text { mezclas. }\end{array}$ & 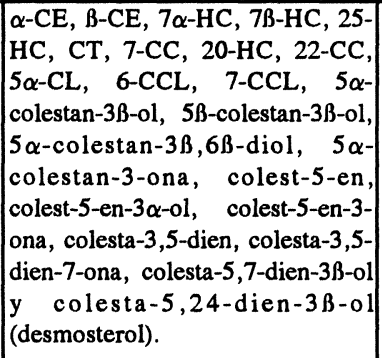 & - & - \\
\hline $\begin{array}{ll}\text { Tsai y } & \text { Hudson, } \\
\text { 1984. } & \end{array}$ & Ovoproductos en polvo. & $\alpha-\mathrm{CE}$ y $\beta-\mathrm{CE}$ & Acetona & - \\
\hline
\end{tabular}

a Patrón interno. 
Tabla II

Métodos en la identificación y/o cuantificación de OE

\begin{tabular}{|c|c|c|c|c|}
\hline $\begin{array}{c}\text { Referencia } \\
\text { bilbliográfica }\end{array}$ & Purificación & Identificación & Cuantificación & $\begin{array}{l}\text { Oxiesteroles } \\
\text { detectados. }\end{array}$ \\
\hline $\begin{array}{l}\text { P r a s a d y } \\
\text { Subramanian, 1992. }\end{array}$ & - & $\begin{array}{l}\text { CCF con gel de } \\
\text { sílice: } R f .\end{array}$ & - & $\begin{array}{l}\text { Identificados: CE y CT. } \\
\text { Observación: el método } \\
\text { no distingue entre los } \\
\text { dos isómeros del CE. }\end{array}$ \\
\hline Sander et al. 1988. & - & $\begin{array}{l}\text { CG: TR y CoC. } \\
\text { CG-EM }(70 \mathrm{ev}) .\end{array}$ & $\begin{array}{l}\text { CG con CC según Park y } \\
\text { Addis, 1985a. }\end{array}$ & $\begin{array}{l}\text { Cuantificados: } \alpha-\mathrm{CE}, \beta- \\
\mathrm{CE}, 7 \alpha-\mathrm{HC}, 7 \beta-\mathrm{HC}, \mathrm{CT} \\
\text { y } 7-\mathrm{CC} \text {. }\end{array}$ \\
\hline Sander et al. 1989. & - & $\begin{array}{l}\text { CG: TR y CoC. } \\
\text { CG-EM }(70 \mathrm{ev}) .\end{array}$ & $\begin{array}{l}\text { Derivatización (TMS) con } \\
\text { Sylon BTZ. } \\
\text { CG con CC DB-1 (de } 180 \\
{ }^{\circ} \mathrm{C} \rightarrow 250^{\circ} \mathrm{C} \text { a } 3^{\circ} \mathrm{C} / \mathrm{min} \text { ). }\end{array}$ & $\begin{array}{l}\text { Cuantificados: todos los } \\
\text { patrones de OE. }\end{array}$ \\
\hline Teng, 1990. & $\begin{array}{l}\text { CCF preparativa con gel de } \\
\text { sílice para separar algunos } \\
\text { OE que no se separan por } \\
\text { CLAE. }\end{array}$ & $\longrightarrow$ & $\begin{array}{l}\text { CLAE con columna } \\
\text { Ultrasphere SIL: } \\
\text {-FM, HEX/ISO (100:2.3, } \\
\text { v/v). } \\
\text {-detector, UV (205 y } 235 \\
\text { nm). }\end{array}$ & $\begin{array}{l}\text { Se da separación de los } \\
\text { patrones ensayados. }\end{array}$ \\
\hline Teng, 1991. & - & \begin{tabular}{|l} 
CCF con gel de \\
sílice de las \\
diferentes fases \\
eluidas en CLAE.
\end{tabular} & $\begin{array}{l}\text { CLAE estudio de la } \\
\text { separación de los patrones } \\
\text { en tres columnas: } \\
\text {-Columna y FM, HEX/ISO } \\
\mu \text {-Porasil } 100: 3 \\
\text { Ultrasphere SIL 100:2 } \\
\text { Zorbax SIL } 100: 2.2 \\
\text {-detector, UV (234 nm para } \\
\text { 7-CC y } 210 \mathrm{~nm} \text { para el resto } \\
\text { de OE). }\end{array}$ & $\begin{array}{l}\text { Se dan cromatogramas } \\
\text { en donde se ve el orden } \\
\text { de elución de los } \\
\text { compuestos en las } \\
\text { diferentes columnas y la } \\
\text { resolución. }\end{array}$ \\
\hline Teng et al., 1973. & $\begin{array}{l}\text { CCF preparativa con gel de } \\
\text { sílice para comprobar la } \\
\text { pureza de los patrones. }\end{array}$ & - & $\begin{array}{l}\text { Sin derivatización. } \\
\text { CG con columnas de } \\
\text { relleno: } 2 \text { y } 3 \% \text { OV-210 y } 2 \\
\text { y } 3 \% \text { SP- } 2401 \text { (en los cuatro } \\
\text { casos a } 230^{\circ} \mathrm{C} \text { ). }\end{array}$ & $\begin{array}{l}\text { Se da separación en las } \\
\text { diferentes columnas de } \\
\text { los patrones ensayados. }\end{array}$ \\
\hline $\begin{array}{l}\text { Tsai y Hudson, } \\
\text { 1981. }\end{array}$ & - & - & $\begin{array}{l}\text { CLAE con columna } \mu \text { - } \\
\text { Porasil: } \\
\text {-Fases móviles, HEX/ISO } \\
\text { (diferentes proporciones, } \\
\text { v/v), HEX/acetato de etilo } \\
\text { (diferentes proporciones, } \\
\text { v/v) y HEX/tetrahidrofurano } \\
\text { (diferentes proporciones, } \\
\text { v/v). } \\
\text {-detector, refractómetro y } \\
\text { UV (210 .nm) al mismo } \\
\text { tiempo. }\end{array}$ & $\begin{array}{l}\text { Se da separación de los } \\
\text { patrones con las } \\
\text { diferentes fases móviles. }\end{array}$ \\
\hline $\begin{array}{lll}\text { Tsai } & \text { y } & \text { Hudson, } \\
1984 . & \end{array}$ & Columna de Bio-Sil HA. & \begin{tabular}{|l} 
EM (70 ev). \\
IR. \\
${ }^{1} \mathrm{H}-\mathrm{RMN}$ \\
$\mathrm{MHz})$
\end{tabular} & $\begin{array}{l}\text { CLAE con columna de } \\
\text { LiChrosorb Si } 60 \text { : } \\
\text {-FM, HEX/ISO }(98: 2, \mathrm{v} / \mathrm{v}) \text {; } \\
\text {-detector, refractómetro. }\end{array}$ & $\begin{array}{l}\text { Identificados: } \alpha \text {-CE y } \beta \text { - } \\
\text { CE. }\end{array}$ \\
\hline
\end{tabular}


Tabla II

Métodos en la identificación y/o cuantificación de OE

\begin{tabular}{|c|c|c|c|c|}
\hline $\begin{array}{c}\text { Referencia } \\
\text { bibliográfica }\end{array}$ & Muestra & Patrones de oxiesteroles & Extracción & Saponificación \\
\hline $\begin{array}{l}\text { Tsai y Hudson, } \\
1985 .\end{array}$ & $\begin{array}{l}\text { Ovoproductos en polvo. Yema } \\
\text { de huevo en polvo obtenida } \\
\text { por atomización con fuente de } \\
\text { calor directa e indirecta a } \\
\text { diferentes temperaturas. }\end{array}$ & $\begin{array}{l}\alpha \text {-CE y } \beta-C E \text {. Patrón externo } \\
\text { una mezcla de } \alpha-C E+\beta- \\
\text { CE. }\end{array}$ & CLO/MET $(2: 1, \mathrm{v} / \mathrm{v})$. & - \\
\hline Tsai et al., 1980. & Ovoproductos en polvo. & $\begin{array}{l}\alpha \text {-CE y } \beta \text {-CE. Patrón externo } \\
\text { una mezcla de } \alpha-C E+\beta- \\
\text { CE. }\end{array}$ & CLO/MET $(2: 1, \mathrm{v} / \mathrm{v})$. & - \\
\hline $\begin{array}{l}\text { Van de Bovenkamp } \\
\text { et al., } 1988 .\end{array}$ & $\begin{array}{|lllr|}\text { Ovoproductos } & \text { en } & \text { polvo. } \\
\text { Componentes } & \text { de la } & \text { dieta } \\
\text { holandesa } & \text { frescos } & \text { y } \\
\text { cocinados. } & & \end{array}$ & $\begin{array}{l}\alpha-\mathrm{CE}, \quad 7 \beta-\mathrm{HC}, 25-\mathrm{HC}, \mathrm{CT} \\
7-\mathrm{CC}, 5 \alpha-\mathrm{CL}^{\mathrm{a}} \text { y betulina }{ }^{\mathrm{a}}\end{array}$ & CLO/MET $(2: 1, \mathrm{v} / \mathrm{v})$ & \\
\hline Yan y White, 1990. & $\begin{array}{l}\text { Manteca de cerdo a la que se } \\
\text { adicionan distintos niveles de } \\
\text { colesterol y se calienta. }\end{array}$ & $\begin{array}{l}\alpha-\mathrm{CE}, 7 \alpha-\mathrm{HC}, 7 \beta-\mathrm{HC}, 25- \\
\mathrm{HC}, \mathrm{CT}, 7-\mathrm{CC} \text { y } 5 \alpha-\mathrm{CL}^{\mathrm{a}}\end{array}$ & & $\begin{array}{l}\text { KOH metanólica } \\
1 \mathrm{~N} \text { (en frío). }\end{array}$ \\
\hline $\begin{array}{l}\text { Zhang y Addis, } \\
1990 .\end{array}$ & 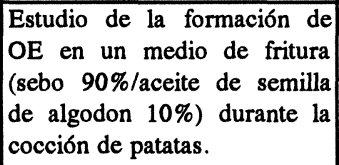 & $\begin{array}{l}\alpha-\mathrm{CE}, \beta-\mathrm{CE}, 7 \alpha-\mathrm{HC}, 7 \beta-\mathrm{HC}, \\
25-\mathrm{HC}, \mathrm{CT}, 7-\mathrm{CC} \text { y } 5 \alpha-\mathrm{CL}^{\mathrm{a}}\end{array}$ & - & $\begin{array}{l}\text { KOH metanólica } \\
\text { 1N (en frío). }\end{array}$ \\
\hline Zhang et al., 1991. & $\begin{array}{l}\text { Patatas fritas en medio de } \\
\text { fritura mezcla de grasa animal } \\
\text { y aceite vegetal. }\end{array}$ & $\begin{array}{l}\alpha-\mathrm{CE}, \beta-\mathrm{CE}, 7 \alpha-\mathrm{HC}, 7 \beta-\mathrm{HC} \\
25-\mathrm{HC}, \mathrm{CT}, 7-\mathrm{CC} \text { y } 5 \alpha-\mathrm{CL}^{\mathrm{a}}\end{array}$ & CLO/MET $(2: 1, \mathrm{v} / \mathrm{v})$ & $\begin{array}{l}\mathrm{KOH} \text { metanólica } \\
1 \mathrm{~N} \text { (en frío). }\end{array}$ \\
\hline $\begin{array}{l}\text { Zubillaga } \\
\text { Merker, 1991. }\end{array}$ & $\begin{array}{l}\text { Carnes (pollo, ternera, buey y } \\
\text { cerdo) frescas y almacenadas } \\
\text { durante diferentes períodos. }\end{array}$ & $\alpha-C E, \beta-C E, 7-C C$ y $6-C^{a}$ & $\begin{array}{l}\text { En columna de una } \\
\text { mezcla de gel de sílice } \\
+\quad \text { Celita } 545 \quad+ \\
\mathrm{C} \text { a } \mathrm{H} \mathrm{PO}_{4} \cdot 2 \mathrm{H}_{2} \mathrm{O} \\
\text { Elución con fracciones } \\
\text { de polaridad creciente. }\end{array}$ & - \\
\hline
\end{tabular}

a Patrón interno. 
Tabla II

Métodos en la identificación y/o cuantificación de OE

\begin{tabular}{|c|c|c|c|c|}
\hline $\begin{array}{c}\text { Referencia } \\
\text { bilbliográfica }\end{array}$ & Purificación & Identificación & Cuantificación & $\begin{array}{l}\text { Oxiesteroles } \\
\text { detectados. }\end{array}$ \\
\hline 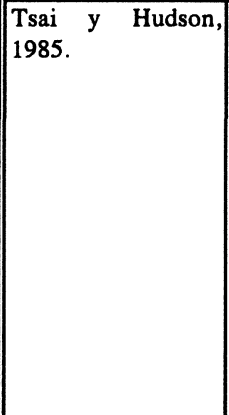 & $\begin{array}{l}\text { Minicolumna de gel de } \\
\text { sílice. }\end{array}$ & $\begin{array}{l}\text { según Tsai } \\
\text { Hudson, } 1984 .\end{array}$ & $\begin{array}{l}\text { Sin derivatización. } \\
\text { CG con CR } 3 \% \text { OV-17 (de } \\
225^{\circ} \mathrm{C} \rightarrow 265^{\circ} \mathrm{C} \text { a } 4^{\circ} \mathrm{C} \text { ) no } \\
\text { separa los dos isómeros del } \\
\text { CE. } \\
\text { CLAE con columna de } \mu- \\
\text { Porasil: } \\
\text {-FM, HEX/ISO (100:3, } \\
\text { v/v); } \\
\text {-detector, refractómetro. } \\
\text { Separa los isómeros del CE } \\
\text { y permite calcular la } \\
\text { relación } \alpha \text {-CE/B-CE. }\end{array}$ & $\begin{array}{l}\text { Cuantificados: } \alpha \text {-CE y } \beta- \\
\text { CE, con CG se halla el } \\
\text { total de CE y con CLAE } \\
\text { se halla la relación entre } \\
\text { los dos isómeros. }\end{array}$ \\
\hline Tsai et al., 1980. & $\begin{array}{l}\text { Minicolumna de gel de } \\
\text { sílice. }\end{array}$ & $\begin{array}{l}\text { CG: TR. } \\
\text { CLAE: TR. }\end{array}$ & $\begin{array}{l}\text { Sin derivatización. } \\
\text { CG con CR } 3 \% \text { OV-17 (de } \\
225^{\circ} \mathrm{C} \rightarrow 265^{\circ} \mathrm{C} \text { a } 4{ }^{\circ} \mathrm{C} \text { ) no } \\
\text { separa los dos isómeros del } \\
\text { CE. } \\
\text { CLAE con columna de } \mu- \\
\text { Porasil: } \\
\text {-FM, HEX/ISO (100:3, } \\
\text { v/v); } \\
\text {-detector, refractómetro. } \\
\text { Separa los isómeros del CE } \\
\text { y permite calcular la } \\
\text { relación } \alpha \text {-CE/ } / \text {-CE. }\end{array}$ & $\begin{array}{l}\text { Cuantificados: } \alpha \text {-CE y } \beta \text { - } \\
\text { CE, con CG se halla el } \\
\text { total de CE y con CLAE } \\
\text { se halla la relación entre } \\
\text { los dos isómeros. } \\
\text { Observaciones: se dan } \\
\text { precisión y recuperación } \\
\text { para CG y precisión para } \\
\text { CLAE. }\end{array}$ \\
\hline $\begin{array}{l}\text { Van de Bovenkamp } \\
\text { et al., } 1988 .\end{array}$ & $\begin{array}{l}1^{\circ} \text { columna de gel de sílice. } \\
2^{\circ} \text { columna de gel de sílice. }\end{array}$ & $\begin{array}{l}\text { CG: TR. } \\
\text { CG-EM. }\end{array}$ & $\begin{array}{l}\text { Derivatización (TMS) con } \\
\text { h ex a m etild is il a za n o / } \\
\text { triclorometilsilan }(2: 1 \text {, v/v). } \\
\text { CG (introducción de la } \\
\text { muestra directamente en } \\
\text { cabeza de columna) con CC } \\
\text { CP-Sil } 5 \text { CB (de } 70{ }^{\circ} \mathrm{C} \rightarrow \\
200^{\circ} \mathrm{C} \text { a } 15^{\circ} \mathrm{C} / \mathrm{min} \text { y de } 200 \\
\left.{ }^{\circ} \mathrm{C} \rightarrow 295^{\circ} \mathrm{C} \text { a } 10^{\circ} \mathrm{C} / \mathrm{min}\right) .\end{array}$ & $\begin{array}{l}\text { Cuantificados: todos los } \\
\text { patrones de OE. } \\
\text { Observaciones: se dan } \\
\text { F R R, prec is i ó n, } \\
\text { recuperaciones y LD. } \\
\end{array}$ \\
\hline Yan y White, 1990. & & $\begin{array}{l}\text { CG: TR. } \\
\text { CG-EM. }\end{array}$ & $\begin{array}{l}\text { Derivatización (TMS) con } \\
\text { Sylon BTZ. } \\
\text { CG con CC DB-1 (de } 80^{\circ} \mathrm{C} \\
\rightarrow 250^{\circ} \mathrm{C} \text { a } 3^{\circ} \mathrm{C} / \mathrm{min} \text { ). }\end{array}$ & $\begin{array}{l}\text { Cuantificados: } \alpha-\mathrm{CE} \\
7 \alpha-\mathrm{HC}, 7 \mathrm{H}-\mathrm{HC}, \mathrm{CT} \text { y } 7- \\
\text { CC. }\end{array}$ \\
\hline $\begin{array}{lll}\text { Zhang y } & \text { Addis, } \\
1990 . & & \\
\end{array}$ & & $\begin{array}{l}\text { CG: TR y CoC. } \\
\text { CG-EM }(70 \mathrm{ev}) .\end{array}$ & $\begin{array}{l}\text { Derivatización (TMS) con } \\
\text { Sylon BTZ. } \\
\text { CG con CC DB-1 (de } 180 \\
{ }^{\circ} \mathrm{C} \rightarrow 250^{\circ} \mathrm{C} \text { a } 3^{\circ} \mathrm{C} / \mathrm{min} \text { ). }\end{array}$ & $\begin{array}{l}\text { Cuantificados: todos los } \\
\text { patrones de OE. }\end{array}$ \\
\hline Zhang et al., 1991. & - & $\begin{array}{l}\text { CG: TR y CoC. } \\
\text { CG-EM }(70 \mathrm{ev}) .\end{array}$ & $\begin{array}{l}\text { Derivatización (TMS) con } \\
\text { Sylon BTZ. } \\
\text { CG con CC DB-1 (de } 180 \\
\left.{ }^{\circ} \mathrm{C} \rightarrow 250^{\circ} \mathrm{C} \text { a } 3^{\circ} \mathrm{C} / \mathrm{min}\right) .\end{array}$ & $\begin{array}{l}\text { Cuantificados: todos los } \\
\text { patrones de OE. }\end{array}$ \\
\hline $\begin{array}{l}\text { u billa ga } \\
\text { Maerker, 1991. }\end{array}$ & $\begin{array}{l}\text { CCF preparativa con gel de } \\
\text { sílice. }\end{array}$ & CG: TR y CoC. & $\begin{array}{l}\text { Sin derivatización. } \\
\text { CG con CC Ultra-2 (3 min a } \\
100^{\circ} \mathrm{C} \text {, de } 100^{\circ} \mathrm{C} \rightarrow 260^{\circ} \mathrm{C} \\
\text { a } 30^{\circ} \mathrm{C} / \mathrm{min} \text {, de } 260^{\circ} \mathrm{C} \rightarrow \\
280^{\circ} \mathrm{C} \text { a } 0.6^{\circ} \mathrm{C} / \mathrm{min} \text {, de } 280 \\
\left.{ }^{\circ} \mathrm{C} \rightarrow 310^{\circ} \mathrm{C} \text { a } 30^{\circ} \mathrm{C}\right) .\end{array}$ & $\begin{array}{l}\text { Cuantificados: todos los } \\
\text { patrones de OE. } \\
\text { Observación: se dan } \\
\text { recuperaciones. }\end{array}$ \\
\hline
\end{tabular}

* Inicio programa de temperatura de horno. 


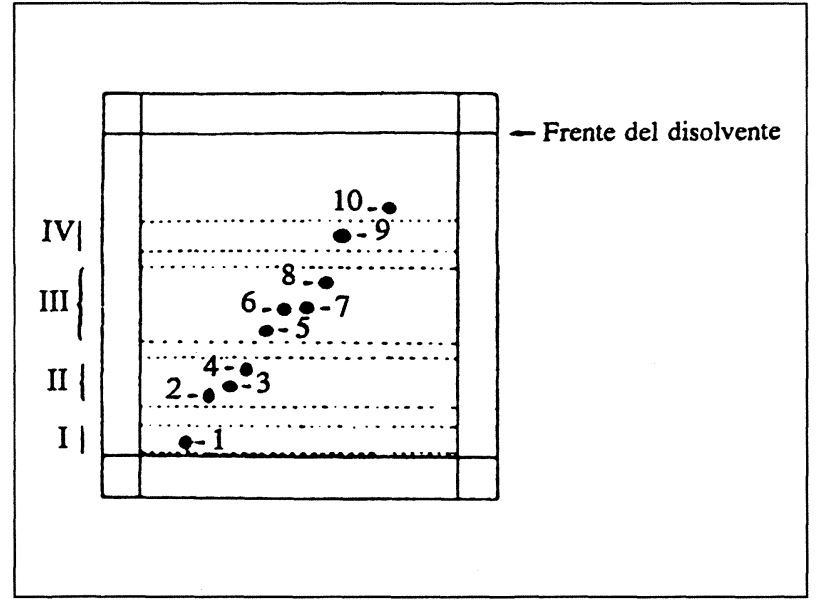

Figura 1

Migración de los patrones eluidos en una placa de gel de sílice con hexano/éter dietílico/acetato de etilo (50:50:50). 1, CT; 2, 7 $\alpha-\mathrm{HC} ; 3,19-\mathrm{HC} ; 4$, 7B-HC; 5, 7-CC; 6, $\alpha$-CE; 7, B-CE; 8, 25-HC; 9, 20-HC; y 10, colesterol (Pie y Seillan, 1992). Cuando se trabaja con muestras reales se rascan, extraen y analizan separadamente por CG las 4 bandas marcadas en la figura con números romanos

\subsection{LA CROMATOGRAFIA DE GASES.}

La cromatografía de gases es el método más utilizado para la determinación de OE en alimentos y muestras biológicas. Inicialmente, se utilizaban columnas de relleno con fases apolares como: SE-30 (100\% metil silicona), OV-17 (50\% fenilmetil silicona), QF-1 o OV-210 (50\% 3,3,3-trifluoropropil silicona), etc. No obstante, actualmente estas columnas han caido prácticamente en desuso, siendo sustituidas por columnas capilares con fases muy apolares como las de $100 \%$ metil silicona (DB-1, CP-Sil 5 CB, Ultral$1, \mathrm{OV}-101$, etc) o un poco menos apolares como las de $5 \%$ fenil + metil silicona (DB-5, CP-Sil 8 CB, Ultra-2, SE-54, etc). En alguna ocasión (Morgan y Armstrong, 1989, 1992) también se han utilizado fases con polaridad intermedia como las de $50 \%$ fenil $+50 \%$ metil silicona (HP-17).

En relación con la polaridad de estas columnas, Park y Addis (1985a) realizaron un estudio en donde compararon la separación que se obtenía con tres columnas de polaridad creciente (DB-1, DB-5 y DB- $1701,1 \%$ vinil $+7 \%$ fenil $+7 \%$ cianopropil $+85 \%$ metil silicona), llegando a la conclusión de que la columna más apolar era la que mejor resolución proveía.

Toda columna empleada en la determinación de OE debe resistir elevadas temperaturas, ya que el punto de ebullición de estos compuestos o de sus derivados silanizados es bastante elevado, llegándose a trabajar a temperaturas de horno de $300^{\circ} \mathrm{C}$ (tabla II).

\subsubsection{Separación.}

Indiscutiblemente, las columnas capilares con fases apolares son las que proporcionan una mayor resolución. La resolución también se ve incrementada mediante la derivatización de los $O E$ en forma de trimetilsilil éteres (TMS). Mediante esta silanización se produce un cambio en los TR y en el orden de elución de los OE (TMS); y, al mismo tiempo, se obtienen picos más estrechos y simétricos, aumentando el número de platos teóricos del sistema cromatográfico (Figura 2). Además, con esta derivatización, se obtiene la ventaja adicional de la termoestabilidad de los productos, con lo cual se evita el problema de descomposición térmica descrito para los 7HCs y otros hidroxicolesteroles no derivatizados (Park y Addis, 1985a; Teng et al., 1973; Van Lier y Smith, 1968).
A

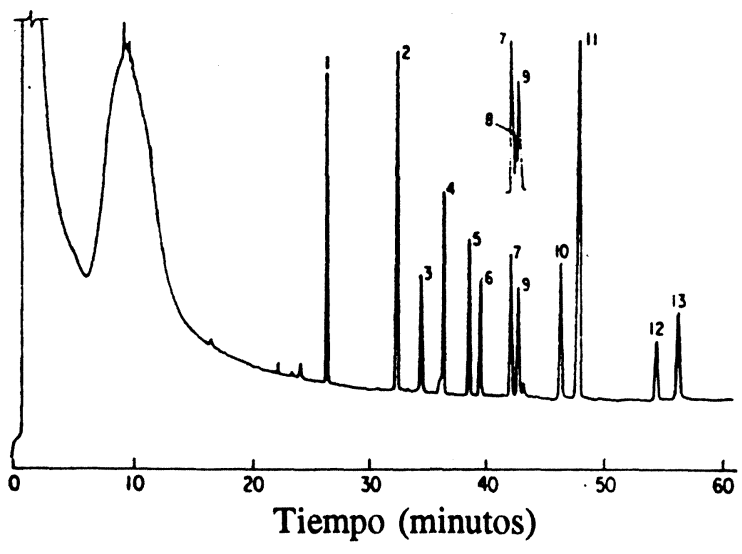

B

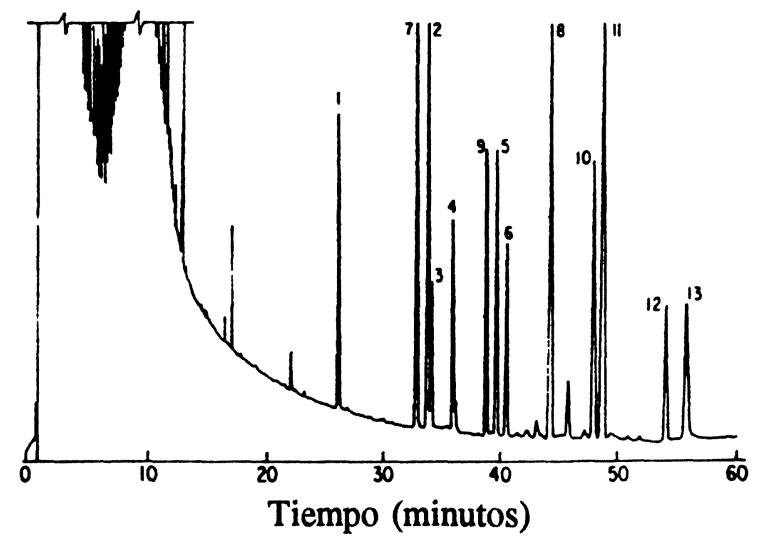




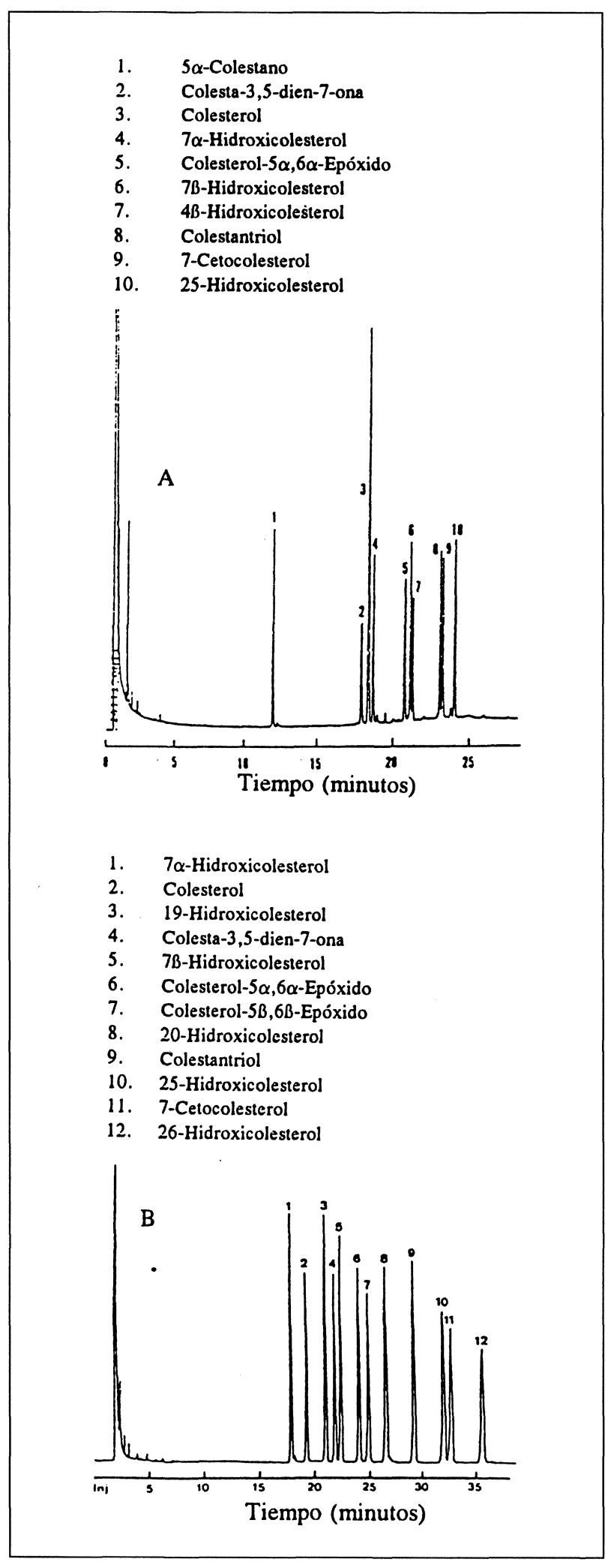

Figura 3

Separación de patrones derivatizados de OE (TMS) columnas de diferente polaridad. (A) columna de metil silicona (Park y Addis, 1985a). (B) columna de $5 \%$ fenil $+95 \%$ metil silicona (Pie et al., 1990).
La silanización de los OE se puede lograr mediante una serie de agentes silanizantes, entre los cuales se encuentran: hexametildisilazano (HMDS), N, O-bis(trimetilsilil)acetamida (BSA), N,O-bis(trimetilsilil)trifluoroacetamida (BSTFA), N-trimetilsililimidazol (TMSI), etc. Como catalizador de esta reacción se suele utilizar el triclorometilsilano (TMCS). Para conseguir esta silanización, normalmente, se disuelve el concentrado final de OE en piridina y se añade el agente silanizante o una mezcla de éste con el catalizador. Las condiciones de reacción dependen, esencialmente, del agente silanizante empleado, siendo el Sylon BTZ (BSATTMCS/TMSI, 3:2:3, vivlv) una de las mezclas silanizantes más potentes y por tanto, también, una de las más empleadas. Concretamente, con esta mezcla de reactivos con sólo 20-30 minutos a temperatura ambiente se consiguen los trimetilsilil éteres. Cabe tener en cuenta que tanto el concentrado de OE como la piridina no deben presentar, en absoluto, humedad, ya que en esta reacción el agua compite con los grupos hidroxil de los OE, con lo cual en su presencia la silanización puede ser incompleta. Por otro lado, estos derivados silanizados permanecen sin hidrolizarse tan sólo unos días a $-20^{\circ} \mathrm{C}$.

La separación de estos derivados silanizados en columnas capilares apolares $(100 \%$ metil silicona y $5 \%$ fenil + metil silicona) ha sido ampliamente estudiada (Korahani et al., 1981; Park y Addis, 1985a; Pie et al., 1990). Se ha observado que en función de la fase varia el TR y orden de elución de los analitos (figura 3).

La inyección de las muestras, mayoritariamente, se realiza trabajando con la técnica de partición (split). No obstante, algunos autores trabajan con inyección de la muestra directamente en la cabeza de la columna (on-column) (tabla II). Con esta última técnica, se evita el problema de la discriminación, que muy posiblemente también se presente en el análisis de los OE (Park y Addis, 1992).

\section{1.2.Identificación.}

Una primera aproximación de la identidad de los picos de una muestra se realiza comparando los TR de los patrones de OE con los de los picos de dicha muestra. A continuación, se vuelve a inyectar la muestra adicionada de uno o varios de los patrones de $\mathrm{OE}$, que presumiblemente corresponden a alguno de los picos de esta muestra. La adición se debe realizar de tal manera que la cantidad de patrón añadida suponga un aumento en el área del pico problema de entre un 50-100 \%. Esta mezcla muestrapatrón(es) se inyecta en el cromatógrafo de gases utilizando diferentes programas de temperatura de horno. Si pico y patrón corresponden a un mismo compuesto se obtendrá, con todos los programas de temperatura ensayados, un pico completamente simétrico. Para los compuestos mayoritarios, previamente a la adición de patrón, se realiza una dilución para trabajar con picos pequeños, en los cuales se observa más fácilmente asimetría o desdoblamiento si pico y patrón no son el mismo compuesto. Con esta técnica de adición de patrones llamada también Cocromatografía se consigue una identificación bastante exacta que en algunas ocasiones es comprobada por CCF con gel de silice o por CLAE (tabla II). Una vez reali- 
zada la identificación se puede pasar a la cuantificación, pero teniendo en cuenta que es prácticamente indispensable confirmar la identificación mediante EM.

\section{1.3.Cuantificación.}

La cuantificación por CG debe presentar como característica más importante una buena repetibilidad. Para ello, se debe optimizar, en primer lugar, el método cromatográfico (condiciones de silanización, conservación de los derivados silanizados, condiciones cromatográficas, condiciones de integración, etc.) y, a continuación, todo el método analítico en sus diferentes fases.

La cuantificación normalmente se realiza por el método del patrón interno, aunque algunos autores han utilizado el del patrón externo (Morgan y Armstrong, 1987; Tsai y Hudson, 1985; Tsai et al., 1980). El patrón interno debe añadirse a la muestra cuanto antes mejor. Con toda certeza, el compuesto más utilizado como PI es el $5 \alpha$-colestano, este compuesto puede añadirse al principio del método analítico, siempre y cuando, no se realice una purificación por CCF con gel de silice o en columna del mismo material, ya que en estos dos casos el $5 \alpha$-colestano eluye con los componentes más apolares de la fracción lipídica y no se recoge junto a los OE. La solución a este problema es buscar un patrón que eluya junto a los $\mathrm{OE}$, como en los trabajos de Pie (Pie y Seillan, 1992; Pie et al., $1990,1991)$, o bien seguir trabajando con el $5 \alpha$-colestano, pero añadiendolo tras la purificación (normalmente previamente a la silanización). En este último caso el PI corrige esencialmente la variabilidad en los volúmenes inyectados, mientras que si se añade al principio corrige, entre otros errores, las posibles pérdidas durante la manipulación de la muestra. La cuantificación utilizando el PI se puede realizar básicamente de dos maneras:

- utilizando los factores de respuesta relativos (FRR);

- utilizando la curva de calibrado.

Los FRR de los OE en forma de trimetilsilil éteres, como norma general, presentan valores próximos a la unidad, siendo los factores de $\alpha$-CE y del 7-CC los que más se alejan de este valor unitario. Este hecho se puede observar en la tabla III, en donde se presentan los FRR para el colesterol y algunos OE calculados por diferentes autores.

Tabla III

FRR del colesterol y de los OE obtenidos por diversos autores

\begin{tabular}{|c|c|c|c|c|c|c|}
\hline Compuesto & Guardiola $^{\mathrm{a}}$ & $\begin{array}{c}\text { Nawar et al. } \\
(1991)^{b}\end{array}$ & $\begin{array}{c}\text { Maerker y Jones } \\
(1992)^{c}\end{array}$ & $\begin{array}{c}\text { Park y Addis } \\
(1985 a)^{a}\end{array}$ & Pie et al. $(1990)^{d}$ & $\begin{array}{l}\text { Van de Bovenkamp } \\
\text { et al. }(1988)^{\mathrm{a}}\end{array}$ \\
\hline Colesterol & 0.88 & 0.74 & 0.97 & 1.00 & $0.92^{e}$ & - \\
\hline$\alpha-\mathrm{CE}^{\mathrm{f}}$ & 1.03 & 0.85 & 1.05 & 1.13 & $1.10^{\mathrm{B}}$ & 1.23 \\
\hline 7ß-HC & 0.98 & 0.86 & 1.14 & 0.98 & $0.99^{8}$ & 0.93 \\
\hline CT & 0.99 & - & 1.36 & 1.03 & $1.13^{\mathrm{g}}$ & 1.07 \\
\hline 7-CC & 1.24 & 0.91 & 1.11 & 1.13 & $1.20^{B}$ & 1.10 \\
\hline 25-HC & 0.94 & - & - & 0.98 & $1.14^{8}$ & 0.93 \\
\hline
\end{tabular}

a Patrón interno $5 \alpha$-colestano. Patrones silanizados.

${ }^{b}$ Patrón interno $5 \alpha$-androstan-3ß-ol-17-ona. Patrones silanizados.

c Patrón interno colesta-5,24-dien-3ß-ol (desmosterol). Patrones sin derivatizar.

${ }^{d}$ Patrones silanizados.

- Patrón interno $5 \alpha$-colestan-3ß-ol (colestanol).

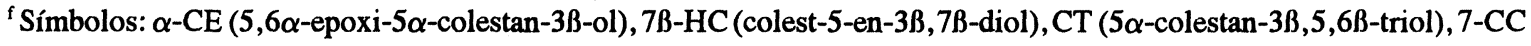

(3ß-hidroxicolest-5-en-7-ona) y 25-HC (colest-5-en-3B,25-diol).

B Patrón interno colest-5-en-3ß,19-diol (19-hidroxicolesterol). 
La cuantificación utilizando curva de calibrado es más exacta que empleando los FRR.

Además, la exactitud de ambos métodos de cuantificación puede mejorarse teniendo en cuenta, para el cálculo de la concentración de los analitos en la muestra, su recuperación y la del PI a lo largo del método analítico.

\subsection{CROMATOGRAFIA LIQUIDA DE ALTA EFICACIA.}

En el análisis de OE, la CLAE va abriéndose camino, día a día, frente al método ampliamente estudiado y utilizado de la CG. Para la determinación de los OE por CLAE se han utilizado columnas con fase normal de gel de sílice y con fase inversa. De estos dos tipos de columna las más introducidas en este análisis son las de fase normal.

La CLAE presenta ventajas y desventajas frente a la CG. Entre las ventajas están la no presencia de problemas de descomposición térmica y que es un análisis con detección no destructiva, con lo cual se pueden recoger los eluatos para posteriores determinaciones, como por ejemplo, para la identificación. No obstante, presenta como desventaja que algunos de los OE son difícilmente detectables por los sistemas de detección utilizados en la CLAE.

\subsubsection{Resolución}

Existen una serie de trabajos en los que se evalúa muy profundamente la capacidad resolutiva de esta técnica con diferentes columnas y fases móviles (Teng, 1990, 1991; Tsai y Hudson, 1981). Para ello, en estos trabajos se utiliza un amplio número de patrones. De los tres estudios citados, en los tres se trabaja con fase normal y posiblemente el más destacable es el de Tsai y Hudson. En este trabajo se compara la separación de 24 patrones en una columna de $\mu$ Porasil utilizando diferentes fases móviles. Las fases móviles ensayadas son: HEX/ISO (a diferentes proporciones), HEX/tetrahidrofurano (a diferentes proporciones) y HEX/acetato de etilo (a diferentes proporciones). De todas estas fases móviles, la mezcla HEX/ISO (100:3, v/v) resultó ser la que proporcionaba una mejor separación. En este trabajo se da el factor de capacidad (K') de cada uno de los 24 compuestos para esta mezcla. El valor de este factor decrece con la adición al hexano de cantidades crecientes de los disolventes polares. El disolvente que provoca una mayor disminución de $\mathrm{K}^{\prime}$ es el isopropanol y, a continuación, el tetrahidrofurano y el acetato de etilo, por este orden. De esta manera, el colesterol fue eluido con una K' de 1.0 con HEX/ISO (100:3), HEX/tetrahidrofurano (100:30) o HEX/acetato de etilo (100:40). Otra de las conclusiones interesantes de este trabajo fue que existe una relación entre el valor de K' de un compuesto y su estructura. La introducción de funciones oxigenadas en la molécula del colesterol implica un aumento de K', el cual depende de la capacidad de la función introducida para formar puentes de hidrógeno y de la posición y orientación en la que se realiza dicha introducción. Este aumento es creciente en el siguiente orden: carbonilo en cadena lateral, hidroxilo en cadena lateral, epóxido en el anillo B, carbonilo en el anillo $B$ e hidroxilo en el anillo B (tabla IV). La introducción de un grupo polar, ya sea hidroxilo o carbonilo, sobre la molécula de colesterol influye en diferente magnitud sobre el valor de ' K' en función de que se realice sobre la cadena lateral o el anillo B. Según estos autores, esto obedece a que el compuesto, que posee dos grupos polares, cuando se adsorbe en la fase estacionaria mediante la formación de un puente de hidrógeno a través de uno de estos dos grupos, el otro grupo queda mucho más accesible para la fase móvil cuanto más separado este de él. Esto explica, por ejemplo, que los factores de capacidad del colest-5-en-3ß,25-diol, colest-5-en-3ß,7ß-diol y colest5-en-3ß,7 $\alpha$-diol con HEX/ISO (100:3) fueran 2.9, 18.5 y 21.7, respectivamente. Según estos datos vemos que también influye sobre el valor de K' la orientación del grupo hidroxilo de C-7. Esto es debido a que cuando este grupo se encuentra situado ecuatorialmente $(7 B-H C)$ el impedimento estérico causado por los hidrógenos de C-15 es mucho mayor que cuando se sitúa axialmente $(7 \alpha-\mathrm{HC})$. Un caso particular es el del CT, compuesto en el cual existen tres grupos hidroxilos, dos más que en el colesterol, situados muy próximos entre ellos. Este hecho confiere al compuesto un valor de $\mathrm{K}^{\prime}$ muy elevado cuando se trabaja con HEX/ISO (100:3, v/v), con lo cual se obtiene un pico muy ancho y tardío, difícilmente cuantificable.

La solución a este problema es utilizar una fase móvil más polar (HEX/ISO, 100:10, v/v) con lo cual el compuesto eluye antes, pero como contrapartida el uso de esta fase móvil (FM) implica una gran disminución en la resolución de los compuestos menos polares.

En un estudio más reciente de Teng (1990), en donde se utiliza una columna de Ultrasphere SIL, se da la separación con HEX/ISO (100:2.3, v/v) de 9 patrones, entre los cuales se encuentran 3 hidroperóxidos del colesterol. La elución a $0.5 \mathrm{ml} / \mathrm{min}$ con esta mezcla de disolventes no consiguió separar los epímeros del 7-HC y, además, el pico correspondiente al $7 \alpha-\mathrm{HC}+7 \beta-\mathrm{HC}$ eluyó con un tiempo de retención muy alto. Posteriormente, Teng (1991) realizó un trabajo en el que comparaba la separación de 12 patrones, entre los cuales figuraban también 3 hidroperóxidos del colesterol, en 3 columnas con fase normal y bajo las siguientes condiciones:

$\begin{array}{lcc}\text { Fase estacionaria } & \text { FM HEX/ISO }(\mathrm{v} / \mathrm{v}) & \text { Velocidad de } \\ & & \\ \mu \text {-Porasil } & 100: 3 & 1 \mathrm{ml} / \mathrm{min} \\ \text { Ultrasphere SIL } & 100: 2 & 1 \mathrm{ml} / \mathrm{min} \\ \text { Zorbax SIL } & 100: 2.2 & 1 \mathrm{ml} / \mathrm{min}\end{array}$

La principal conclusión de este trabajo fue que la resolución de estas columnas depende del número de grupos silanol ( $\mathrm{Si}-\mathrm{OH})$ superficiales presentes en la columna lo cual depende del tamaño de las partículas de gel de silice, de su diámetro de poro y, como es lógico, del tamaño de la propia columna. Las columnas de $\mu$-Porasil y Zorbax SIL presentaron mejor resolución que la de Ultrasphere SIL, columna en la cual no se separan los epímeros del 7-HC. No obstante, en el caso de que el objeto del análisis fueran sólo los hidroperóxidos del colesterol esta última columna 
sería la más indicada por presentar buena resolución y un tiempo de análisis corto para estos compuestos. En estos dos estudios de Teng ( 1990 y 1991), como en el de Tsai y Hudson (1981), se presentaba el problema de que los compuestos más polares eluían muy tardíamente y con picos muy anchos, difícilmente cuantificables. Este hecho cuestiona la aplicabilidad de estos métodos isocráticos al análisis de muestras. Tanto es así, que sólo se han aplicado para determinar OE de polaridad parecida. Los mismos Tsai y Hudson (1984 y 1985), con posterioridad a su trabajo de 1981, utilizaron la CLAE tan sólo para cuantificar $\alpha-C E$ y $ß-C E$. En relación con el tema existen una serie de trabajos que sólo cuantifican C-7 OE (Herian y Lee, 1985; Park y Addis, 1985b).

Tabla IV

Factores de capacidad ( $\left.K^{\prime}\right)$ en una columna de $\mu$-Porasil de una serie de compuestos con el núcleo del colestano (Tsai y Hudson, 1981).

\begin{tabular}{|c|c|c|c|}
\hline & \multicolumn{3}{|c|}{ FASE MÓVIL } \\
\hline & $\begin{array}{c}\text { HEX/ISO } \\
(100: 3) \\
\end{array}$ & $\begin{array}{c}\text { HEX/ISO } \\
(100: 10) \\
\end{array}$ & $\begin{array}{c}\text { HEX/acetato de etilo } \\
(100: 5)\end{array}$ \\
\hline PATRONES & $\mathrm{K}^{\prime \mathrm{a}}$ & $\mathrm{K}^{\prime}$ & $\mathrm{K}^{\prime}$ \\
\hline $5 \alpha$-colestano & 0.05 & & 0.05 \\
\hline colest-5-en & 0.05 & & 0.05 \\
\hline colesta-3,5-dien & 0.05 & & 0.05 \\
\hline colesta-3,5-dien-7-ona & 0.14 & & 0.70 \\
\hline $5 \alpha$-colestan-3-ona & 0.22 & & 1.4 \\
\hline colest-5-en-3-ona & 0.30 & & 1.6 \\
\hline colest-5-en-3 $\alpha$-ol & 0.46 & & 5.1 \\
\hline 5ß-colestan-3ß-ol & 0.70 & & 6.5 \\
\hline colest-5-en-3ß-ol & 1.0 & 0.38 & 10.4 \\
\hline $5 \alpha$-colestan-3ß-ol & 1.1 & & \\
\hline colesta-5,24-dien-3ß-ol & 1.2 & & \\
\hline colesta-5,7-dien-3ß-ol & 1.2 & & \\
\hline 3ß-hidroxicolest-5-en-22-ona & 1.4 & & \\
\hline colest-5-en-3ß,20-diol & 1.5 & 0.38 & \\
\hline colest-5-en-3ß,25-diol & 2.9 & 0.70 & \\
\hline $5,6 \alpha$-epoxi-5 $\alpha$-colestan-3ß-ol & 4.4 & 1.0 & \\
\hline 5,6ß-epoxi-5ß-colestan-3ß-ol & 5.0 & & \\
\hline 3ß-hidroxi- $5 \alpha$-colestan-6-ona & 5.8 & & \\
\hline 3ß-hidroxi-5 $\alpha$-colestan-7-ona & 7.3 & & \\
\hline 3ß-hidroxicolest-5-en-7-ona & 7.6 & 1.4 & \\
\hline colest-5-en-3ß,7ß-diol & 18.5 & 2.2 & \\
\hline 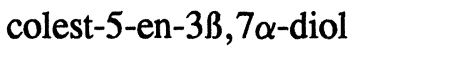 & 21.7 & 2.7 & \\
\hline $5 \alpha$-colestan- $3 \beta, 6 \beta$-diol & 21.7 & 3.1 & \\
\hline 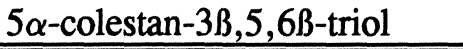 & $>50.0$ & 12.2 & \\
\hline
\end{tabular}

${ }^{a} K^{\prime}=\left(V_{R}-V_{0}\right) / V_{0}$, donde $V_{R}$ es el volúmen de retención del compuesto y $V_{0}$ el volúmen de retención de un compuesto no retenido. 
Por otro lado, Csallany et al. (1989), por ejemplo, desarrollaron un método isocrático (HEX/ISO, 93:7, v/v) con columna de $\mu$-Porasil para determinar $\mathrm{C}-7 \mathrm{OE}$, en la misma columna también determinaron $25-\mathrm{HC}$, pero usando HEX/ISO (97:3, v/v). Como hemos visto, los métodos isocráticos no son válidos para determinar, de una forma precisa y exacta, $O E$ que difieran mucho en polaridad.

La solución a este problema se encuentra en la elución mediante gradientes de polaridad. En un trabajo de Maerker et al. (1988), en el que se utilizaron patrones, la elución se programó de la siguiente forma: en $15 \mathrm{~min}$ se pasó de $100 \%$ de la mezcla A (HEX/ISO, 97:3) a $98.5 \%$ de A y $1.5 \%$ del disolvente B (ISO); en los 10 minutos siguientes se llegó hasta el $97 \%$ de A y el $3 \%$ de $\mathrm{B}$; y finalmente durante los últimos 15 minutos la elución se realizó con $50 \%$ de A y $50 \%$ de B. Con este método se obtuvieron picos simétricos y buena resolución. La aplicación de una elución con un gradiente lineal (0-10 $\%)$ de butanol en hexano permitió determinar en mantequilla, al mismo tiempo, 25-HC, 4B-HC, 7-CC, $7 \alpha-\mathrm{HC}$ y $7 ß-\mathrm{HC}$, con columna de Nucleosil $\mathrm{NO}_{2}$.

Por otro lado, la CLAE con fase inversa se encuentra todavía en un estado de evolución menos avanzado, presentando problemas de resolución prácticamente idénticos a los de la CLAE con fase normal. Para evitar estos problemas de resolución, en un trabajo de Higley et al. (1986), se determinan en carnes y productos cárnicos los OE menos polares $(22-\mathrm{CC}, 19-\mathrm{HC}, 6-\mathrm{CC}, 7 \alpha-\mathrm{HC}$ y $7 B-H C$ ) por CLAE fase normal y el CT por CLAE fase inversa. De esta manera, se realizan dos análisis para cada muestra, lo cual implica un tiempo de análisis largo, pero, por otro lado, permite una buena resolución y la determinación de un amplio número de compuestos. Entre los estudios en los que se trabaja con fase inversa destaca el de Finocchiaro et al. (1984) en el cual se determinan en productos lácteos $\mathrm{OE}$ con polaridad bastante diferenciada: CT, $7 \alpha-\mathrm{HC}, 7 \beta-\mathrm{HC}, \beta-\mathrm{CE}$ y $\alpha-\mathrm{CE}$. En este trabajo se utilizó una columna $\mu$-Bondapak $\mathrm{C} 18$ y como fase móvil ACE/agua (9:1, v/v).

\subsubsection{Detección e identificación.}

El sistema de detección más utilizado en la CLAE es el espectrofotométrico UV (tabla II). No obstante, no todos los OE absorben en la zona del UV y la mayoría de los que lo hacen, lo hacen débilmente. Concretamente, los colesterol epóxidos y el CT no absorben en esta zona. La mayoría de los OE que se encuentran en alimentos se detectan a longitudes de onda inferiores a 212 $\mathrm{nm}$, constituyendo una excepción a esta regla el 7-CC por detectarse normalmente a $233 \mathrm{~nm}$. En la figura 4 se presentan los espectros de absorción al UV de los OE más comunes, en esta figura se observa que el 7-CC presenta un máximo de absorción aproximadamente 3 veces superior al resto de OE, con lo cual no existen problemas de detección para este compuesto. En cambio, la detección por este sistema es más problemática para el resto de OE e imposible para el CT y los colesterol epóxidos.
Este problema se ha intentado solucionar mediante una derivatización de los OE, consistente en la esterificación de sus grupos hidroxilo con grupos benzoato o dinitrobenzoato. Con esta esterificación se consigue un aumento de la absorción en la zona UV. Los derivados benzoilados presentan su máximo de absorción a 230 $\mathrm{nm}$, mientras que los dinitrobenzoilados lo presentan a $254 \mathrm{~nm}$. El agente derivatizante empleado es, respectivamente, cloruro de benzoilo y cloruro de dinitrobenzoilo. La utilización de estos sistemas de derivatización arranca de los años 70 (Carey y Persinger, 1972; Fitzpatrick y Siggia, 1973), pero recientemente han sido revisados en un trabajo de Fillion y Zee (1991), en el cual se concluye que la benzoilación es más útil que la dinitrobenzoilación. En estas derivatizaciones son factores críticos las condiciones de reacción y la estabilidad de los derivados, que son fácilmente hidrolizables. Fillion y Zee en su trabajo dan condiciones de benzoilación en las que se obtiene un máximo rendimiento de la reacción y una estabilidad de los derivados durante dos días. Las ventajas de estas derivatizaciones son: la detección del CT y epóxidos de colesterol; el aumento de la sensibilidad en general; y la utilización de una única longitud de onda para la detección de todos los analitos. A pesar de todas estas ventajas, estas derivatizaciones han sido poco empleadas en la determinación de OE, ya que la reacción de derivatización introduce alta variabilidad y los compuestos resultantes son fácilmente hidrolizables.

Por otro lado, otro de los sistemas de detección ampliamente utilizado en el análisis de OE por CLAE es el refractométrico (tabla II). La ventaja de este sistema es que es universal, pero su desventaja es que presenta baja sensibilidad. En algunos trabajos, este sistema se utiliza combinado con el espectrofotómetro para detectar los OE que no presentan absorción al UV (Finocchiaro et al., 1984; Tsai y Hudson, 1981).

Además de estos dos sistemas de detección también se han utilizado como detectores el de EM (Park y Addis, 1992) y, bastante recientemente, el DIL (Maerker et al., 1988).

La identificación de estos compuestos mediante CLAE se efectúa de forma idéntica a como se realiza en la $C G$, mediante TR y cocromatografía. En ciertas ocasiones la identificación se comprueba por CCF con gel de sílice. Una vez realizada la identificación se puede pasar a la cuantificación, pero teniendo en cuenta que es prácticamente indispensable confirmar la identificación mediante espectrometría de masas.

\subsubsection{Cuantificación.}

El método de cuantificación más utilizado es el del patrón externo (tabla II). En caso de utilizar como detector el espectrofotómetro UV no se puede emplear un único patrón como patrón externo, ya que los $\mathrm{OE}$ responden de forma diferente frente a este detector. Por otro lado, en un trabajo de Park y Addis (1987) se utilizó el método del $\mathrm{PI}$. El compuesto utilizado como patrón interno fue en este caso la 7-cetopregnenolona. 


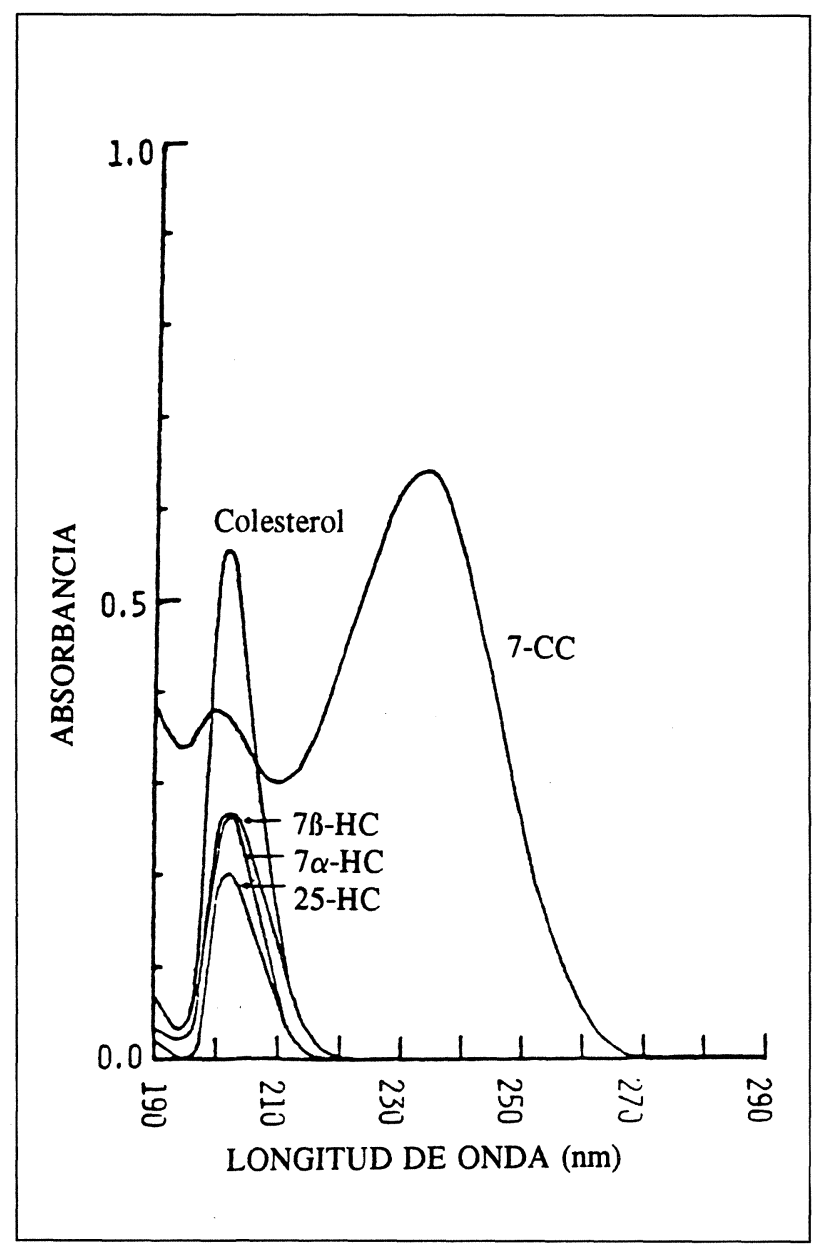

Figura 4

Espectros de absorción al UV de los OE más comunes (Csallany et al., 1989)

\section{CONFIRMACION DE LA IDENTIFICACION POR ESPECTROMETRIA DE MASAS.}

La espectrometría de masas en el análisis de OE se aplica básicamente para confirmar la identificación de posibles OE separados por cromatografía. Esto se hace comparando los espectros de masas de estos posibles $\mathrm{OE}$ con los de los patrones. La espectrometría de masas cada vez es más importante en este análisis y existen muchos trabajos en los que aparecen los espectros de masas de los OE, ya sea en forma de trimetilsilil (TMS) éteres o bien sin derivatizar (tabla V). Gracias a esto, se pueden establecer de forma inequívoca los iones característicos de los $\mathrm{OE}$ más comúnmente analizados, lo que resulta muy útil como trabajo de referencia.

Ocasionalmente, la espectrometría de masas se ha utilizado en el análisis de OE para elucidar estructuras.

\subsection{IONES CARACTERISTICOS DE LOS OXIESTEROLES EN FORMA DE TRIMETILSILIL ETERES.}

Los OE por CG comúnmente se analizan en forma de trimetilsilil éteres y por tanto sus espectros de masas en esta forma son relativamente conocidos.

TMS éteres de los 7-hidroxicolesteroles: La diferenciación de estos dos epímeros es básicamente cromatográfica, ya que sus espectros de masas son prácticamente idénticos. Estos dos compuestos presentan unos espectros bastante sencillos en donde el pico más intenso posee $\mathrm{m} / \mathrm{z} 456$ (M-90) y otros picos característicos poco intensos son: 546 (M), 441 (M-90-15), 366 (M-180) y 351 (M-180-15) (tabla V). En cambio, otros hidroxicolesteroles como el $4 ß-\mathrm{HC}$ dan lugar a espectros mucho más complicados. EI

Tabla V

Referencias bibliográficas en donde aparecen espectros de masas de algunos OE

\begin{tabular}{||c|c|c||}
\hline \multicolumn{3}{|c|}{ Diferentes formas de los OE } \\
Sin & $\begin{array}{c}\text { Derivatizados en forma de } \\
\text { Trimetilsilil éteres }\end{array}$ & $\begin{array}{c}\text { Combinaciones de OE } \\
\text { con otras moléculas }\end{array}$ \\
\hline $\begin{array}{c}\text { Cleveland y Harris, 1987 } \\
\text { De Vore, 1988 }\end{array}$ & Aringer y Eneroth, 1974 & Pannecoucke et al. 1992 \\
Finocchiaro et al., 1984 & Nouroozs et al., 1968, 1973 & \\
Gray et al., 1971 & 1987, 1989 Appelqvist, & \\
& Park y Addis, 1985a, 1986a, & \\
1987, 1989, 1992 & \\
Park y Addis, 1985b, 1992 & Zhang et al., 1991 & \\
Tsai y Hudson, 1984 & & \\
\hline
\end{tabular}


4B-HC presenta los siguientes picos característicos con una intensidad notable: 541 (M), 456 (M-90), 417 y 366 (M-180). Además también presenta otro pico intenso que es el 129, pico característico de todos los esteroles con un doble enlace en la posición 5 (Dumazer et al., 1986).

TMS éteres de hidroxicolesteroles con grupo hidroxilo en la cadena lateral: El más importante de estos $\mathrm{OE}$ es el $25-\mathrm{HC}$ que presenta el pico base a m/z 131 y otros picos característicos menos intensos a $546(\mathrm{M}), 531$ (M-15), 456 (M-90), 441 (M-90-15), 366 (M-180), 351 (M-180-15), 327 y 271 (figura 5). Algunos de estos últimos picos no se aparecen en todos los trabajos revisados. El espectro de masas del $20-\mathrm{HC}$ presenta el pico base a $\mathrm{m} / \mathrm{z} 201$ y otro pico característico a m/z 461 (M-85).

TMS éteres de los colesterol epóxidos: Los iones más característicos de estos dos epímeros son los presentes a $474(\mathrm{M})$ y a $384(\mathrm{M}-90)$. Los espectros de estos compuestos son muy parecidos pero existen algunas diferencias entre ellos. No obstante, estas diferencias son ampliamente controvertidas. Los picos a m/z 366 y 369 (M$90-15)$ han sido observados en el $\alpha-C E ;$ en cambio, en el B-CE Park y Addis (1986a) sólo observaron el pico a 369, mientras que otros autores también observaron el pico a 366 (Aringer y Eneroth, 1974; Nourooz-Zadeh y Appelqvist, 1987). Por otro lado, los iones a m/z 459 (M-15) y 456 también son característicos de estos dos epímeros. Esta controversia no tiene mayor importancia, ya que estos picos se diferencian cromatográficamente, de forma clara.

TMS éteres del 7-cetocolesterol: En algunos trabajos el ion molecular de este compuesto $(\mathrm{m} / \mathrm{z} 472)$ fue el pico base. Otros dos picos a m/z 382 (M-90) y 367 (M-90-15) presentan intensidades considerables. Además, existen otros iones característicos no citados en todos los trabajos como son: 457 (M-15), 187, 174 y 161 (figura 6). Es importante mencionar que el pico base del espectro se encuentra a m/z 472 cuando se utilizan sectores magnéticos (Park y Addis, 1985a; Brooks et al. 1968) y a m/z 129 cuando se utiliza el sistema de los cuatro polos (cuadrupolo) (Park y Addis 1986a; Guardiola).

TMS éter del CT: EI CT presenta tres grupos hidroxilo. Una completa trimetilsilil eterificación de los tres grupos hidroxilo se consiguió calentando a $60^{\circ} \mathrm{C}$ durante $60 \mathrm{hr}$ con una mezcla de BSA/TMCS/TMSI (3:2:3) (Brooks et al., 1968). Cuando la derivatización se realizó a temperatura ambiente durante $1 \mathrm{hr}$ se formó el bis-TMS éter en lugar del tris-TMS éter, siendo el hidroxilo no silanizado el de la posición $5 \alpha$, que es el más estéricamente impedido. Los espectros de masas de estos dos derivados fueron muy parecidos. No obstante, el pico base para el bis-TMS se situó a m/z 129 mientras que para el tris-TMS lo hizo a 456 (Brooks et al., 1973). Más recientemente, Park y Addis (1989) reincidieron sobre el tema en un estudio en donde se comprobó que, cuando la derivatización se realizaba con BSA/TMCS/TMSI (3:2:3) a $70{ }^{\circ} \mathrm{C}$ por un largo período de tiempo, a expensas del pico de bis-TMS iba apareciendo un

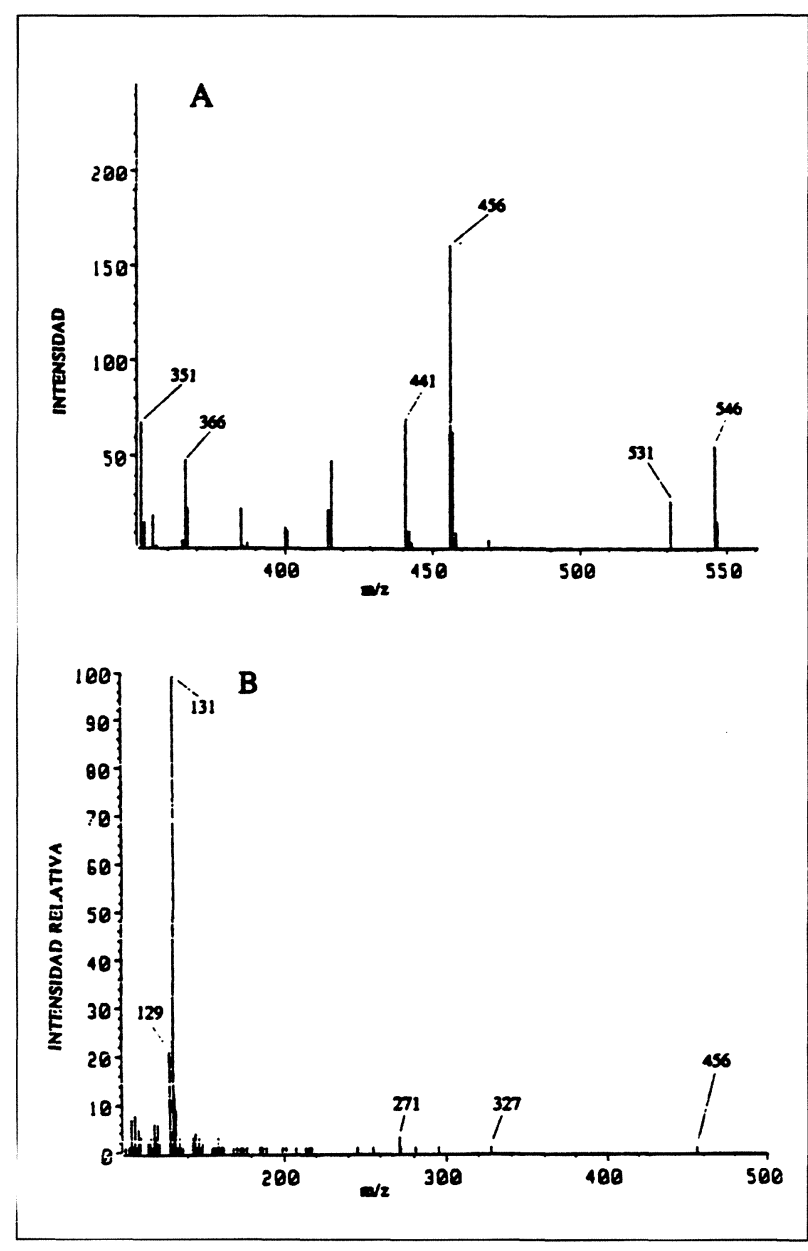

Figura 5

Espectros de masas del 25-HC en forma de TMS éter. (A) Ampliación de la zona final del espectro sin normalizar. (B) Espectro normalizado (Guardiola).

nuevo pico de tris-TMS. Estos dos picos perfectamente diferenciados de forma cromatográfica presentaron espectros de masas muy parecidos. No obstante, en el espectro de masas del tris-TMS aparecen dos picos a m/z 636 (M) y $621(\mathrm{M}-15)$ no presentes en el espectro de masas del bisTMS, en donde, en cambio, aparece un pico exclusivo de él a m/z 564 (M). Así, mediante estos tres picos se diferencian de forma clara estos dos derivados del CT. Por otro lado, existen una serie de picos comunes a ambos compuestos que se sitúan a $\mathrm{m} / \mathrm{z}$ : $546,531,456,441,403$ 367 y 321 . En algunos trabajos se detecta un pico a $\mathrm{m} / \mathrm{z}$ 351 (Park y Addis 1987; Guardiola).

\subsection{IONES CARACTERISTICOS DE LOS OXIESTE- ROLES SIN DERIVATIZAR.}

El análisis de OE por CLAE se realiza normalmente sin derivatización previa. Para la identificación de estos compuestos se puede utilizar la introducción directa del analito puro, procedente de la elución de la muestra por CLAE, 


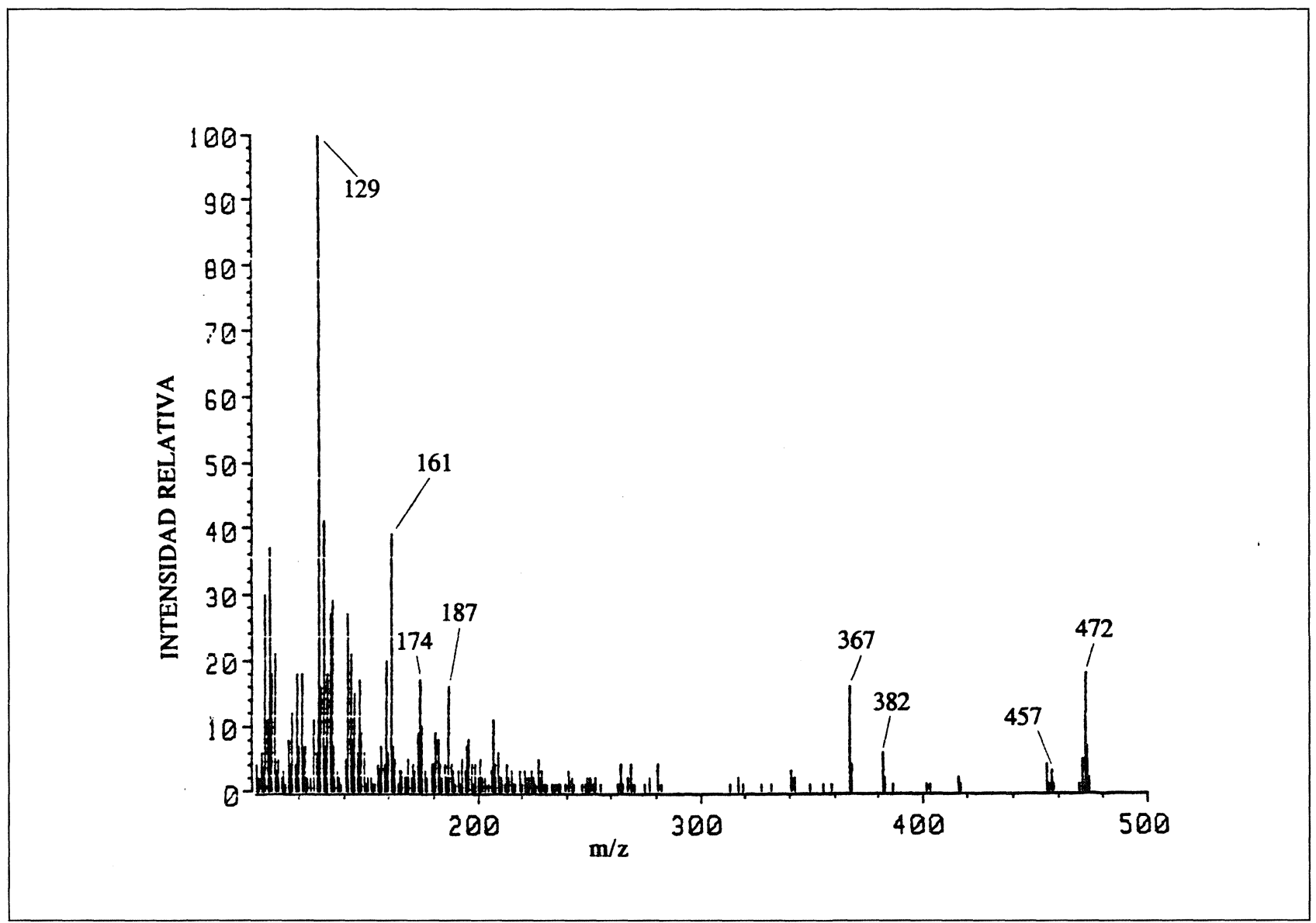

Figura 6

Espectros de masas del 7-CC en forma de TMS éter (Guardiola).

en la cámara de ionización del espectrómetro de masas o, en contadas ocasiones, la CLAE acoplada directamente a la EM.

7-HCs: Ambos epímeros presentan espectros de masas muy parecidos con el pico base situado a $\mathrm{m} / \mathrm{z} 384$ (M-18). Otros picos característicos son: 402(M), 366 (M-18-18), 351 (M-18-18-15) y 247 (M-42-cadena lateral) (tabla V).

25-HC: Para este compuesto Kou y Holmes (1985) observaron los siguientes iones característicos a m/z: 402 (M), $384(\mathrm{M}-18)$ y $369(\mathrm{M}-18-15)$.

Colesterol epóxidos: Los espectros de estos dos epímeros son bastante parecidos y presentan sus picos característicos a m/z $402(\mathrm{M}), 384$ (M-18), 369 (M-18-15), 271 (M-18-cadena lateral), 247 (M-42-cadena lateral) y 229 (M-18-42-cadena lateral). No obstante, Tsai y Hudson (1984) observaron que a m/z 331 aparece un pico en el espectro del $\alpha-C E$ que no lo hace en el del B-CE y además que el $\alpha-C E$ presenta a 356 un pico mucho más intenso que el que presenta el $B-C E$.

7-CC: El pico base se sitúa a m/z 400 (M), otros picos observados en el espectro de masas se encuentran a $\mathrm{m} / \mathrm{z}$ 382 (M-18), 367 (M-18-15), 287 (M-cadena lateral), 205, 192 y 174 (De Vore, 1988; Park y Addis, 1985b).

CT: Para este compuesto Finocchiaro et al. (1984) observaron los siguientes iones característicos a m/z: 420 (M), 402 (M-18), 387 (M-18-15), 366 (M-18-18), 351 (M-1818-15), 271 (M-18-cadena lateral), 247 (M-42-cadena lateral) y 229 (M-18-42-cadena lateral).

\section{AGRADECIMIENTOS}

Queremos agradecer la inestimable colaboración de Carmen Sala Villaplana en la parte gráfica del trabajo. Este trabajo ha sido realizado, en parte, gracias a una beca de la CIRIT. 


\section{BIBLIOGRAFIA}

Acker, L. y Greve, H. (1963).- "Uber die Photoxydation des Cholesterins in Eihaltigen Lebensmitteln".- Fette Seif Anstrich. 65, 1009-1012.

Addis, P.B., Emanuel, H.A., Bergmann, S.D. y Zavoral, J.H. (1989)."Capillary GC quantification of cholesterol oxidation products in plasma lipoproteins of fasted humans".- Free Radical Biol. Med. 7, 179-182.

Aringer, L. y Eneroth, P. (1974).- "Formation and metabolism in vitro of 5,6epoxides of cholesterol and B-sitosterol".- J. Lipid Res. 15, 389-398.

Bascoul, J., Domergue, N., Olle, M. y Crastes de Paulet, A. (1986)."Autoxidation of cholesterol in tallows heated under deep frying conditions: evaluation of oxysterols by GLC and TLC-FID".- Lipids 21, 383-387.

Bergström, S. y Wintersteiner, O. (1941).- "Autoxydation of sterols in colloidal aqueous solutions. The nature of the products formed from cholesterol".- J. Biol. Chem. 141, 597.

Bischoff, F. (1969).- "Carcinogenic effect of steroids".- En Advances in lipid research. (R. Paoletti y D. Kritchevsky, Ed.), p. 165. Academic Press, Nueva York ciudad, Nueva York, EUA.

Brooks, C.J.W., Henderson, W. y Steel, G. (1973).- "The use of trimethylsilyl ethers in the characterization of natural sterols and steroid diols by gas chromatography-mass spectrometry".- Biochim. Biophys. Acta. 296, 431445.

Brooks, C.J.W., Horning, E.C. y Young, J.S. (1968).- " Characterization of sterols by gas chromatography-mass spectrometry of the trimethylsily ethers".- Lipids. 3, 391-402.

Carey, M.A. y Persinger, H.E. (1972).- "Liquid chromatographic determination of traces of aliphatic carbonyl compounds and glycols as derivatives that contain the dinitrophenyl group".- J. Chromatogr. Sci. 10, 537-543.

Cleveland, M. Z. y Harris, N.D. (1987).- "Oxidation of cholesterol in commercially processed cow's milk" - J. Food Prot. 50, 867-871.

Csallany, A. S., Kindom, S. E., Addis, P. B. y Lee, J.H. (1989).- "HPLC method for quantitation of cholesterol and four of its major oxidation products in muscle and liver tissues".- Lipids 24, 645-651.

Csiky, I. (1982).- "Trace enrichment and separation of cholesterol oxidation products by absorption high performance liquid chromatography".- $J$. Chromatogr. 24, 381-389.

Chicoye, E., Powrie, W.D. y Fennema, 0. (1968a).- "Photoxidation of cholesterol in spray-dried egg yolk upon irradiation".- J. Food Sci. 3, 581587.

Chicoye, E., Powrie, W.D. y Fennema, 0. (1968b).- "Isolation and characterization of cholesterol-5ß,6ß-oxide from an aerated aequeous dispersion of cholesterol".- Lipids 3, 335-339.

Chicoye, E., Powrie, W.D. y Fennema, 0. (1968c).- "Synthesis, purification and characterization of 7-ketocholesterol and epimeric 7 . hydroxycholesterols".- Lipids 3, 551-556.

De Vore, V.R. (1988).- "TBA values and 7-ketocholesterol in refrigerated raw and cooked ground beef".- J. Food Sci. 53, 1058-1061.

Doormaal, J.J., Smit, N., Koopman, B.J., Van Der Molen, J.C., Wolthers, B.G. y Doorenbos, H. (1989).- "Hydroxycholesterols in serum from hypercholesterolaemic patients whith and without bile acid sequestrant therapy".- Clin. Chim. Acta. 181, 273.

Dumazer, M., Farines, M. y Soulier, J. (1986).- "Identification de stérols par spectrométrie de masse".- Rev. Fr. Corps Gras 33, 151-156.

Emanuel, H.A., Hassel, C.A., Addis, P.B., Bergmann, S.D. y Zavoral, J.H. (1991).- "Plasma cholesterol oxidation products (oxysterols) in human subjects fed a meal rich in oxysterols".- J. Food Sci. 56, 843-847.

Fillion, L., Zee, J.A. y Gosselin, C. (1991).- "Determination of a cholesterol oxide mixture by a single-run high-perfomance liquid chromatographic analysis using benzoylation".- J. Chromatogr. 547, 105-112.

Finocchiaro, E.T., Lee, K. y Richardson, T. (1984).- "Identification and quantification of cholesterol oxides in grated cheese and bleached butteroil".- J. Am. Oil Chem. Soc. 61, 877-883.

Fitzpatrick, F.A. y Siggia, S. (1973).- "High resolution liquid chromatography of derivatized non-ultraviolet absorbing hydroxy steroids".- Anal. Chem. 45, 2310-2314

Flanagan, V.P., Ferretti, A., Schwartz, D.P. y Ruth, J.M. (1975)."Characterization of two steroid ketones and two isoprenoid alcohols in dairy products".- J. Lipid. Res. 16, 97-101.

Folch, J., Lees, M. y Sloane Stanley, G.H. (1957).- "A simple method for the isolation and purification of total lipids from animal tissues".- J. Biol. Chem. 226, 497-509.

Fontana, A., Antoniazzi, F., Cimino, G., Mazza, G., Trivellone, E. y Zanone B. (1992).- "High resolution NMR detection of cholesterol oxides in spray-dried egg yolk".- J. Food Sci. 57, 869-879.

Gray, M.F., Lawrie, T.D.V. y Brooks, C.J.W. (1971).- "Isolation and identification of cholesterol $\alpha$-oxide and other minor sterols in human serum".- Lipids 6, 836.

Gruenke, L.D., Graig, J.C., Petrakis, N.L. y Lyon, M.B. (1987).- "Analysis of cholesterol, cholesterol-5,6-epoxides and cholestane- $3 \beta, 5 \alpha, 6 \beta$-triol in nipple aspirates of human breast fluid by gas chromatography/mass spectronetry". - Biomed. Environ. Mass Spectrom. 14, 335-338.

Herian, A.M. y Lee, K. (1985).- "7 $\alpha$ - and 7B-hydroxycholesterols formed in a dry egg nog mix exposed to fluorescent light".- J. Food Sci. 50, 276-277.

Higley, N.A., Taylor, S.L., Herian, A.M. y Lee, K. (1986).- "Cholesterol oxides in processed meats" - Meat Sci. 16, 175-188.

Hubbard, W.D., Sheppard, A.J., Newkirk, D.R., Prosser, A.R. y Osgood, T. (1977).- "Comparison of various methods for the extraction of total lipids, fatty acids, cholesterol, and other sterols from food products".- $J$. Am. Oil Chem. Soc. 54, 81-83.

Hwang, K.T. y Maerker, G. (1993).- "Quantitation of cholesterol oxidation products in unirradiated and irradiated meats".- J. Am. Oil Chem. Soc. 70, 371-375.

Ibrahim, N., Unklesbay, N., Kapila, S. y Puri, R.K. (1990).- "Cholesterol content of restructured pork/soy hull mixture".- J. Food Sci. 55, 14881490.

Jacobson, M.S. (1987).- "Cholesterol oxides in indian ghee: possible cause of unexplained high risk of atherosclerosis in indian immigrant populations".- Lancet septiembre 19,656-658.

Kaneda, T., Nakajima, A., Fujimoto, K., Kobayashi, T., Kiriyama, S., Ebihara, K., Inmami, T., Tsuji, K., Tsuji, E., Kinumaki, T., Shimma, H. y Yoneyama, S. (1980).- "Quantitative analysis of cholesterol in foods by gas-liquid chromatography".- J. Nutr. Sci. Vitaminol. 26, 497-505.

Koopman, B.J., Van Der Molen, J.C. y Wolthers, B.G. (1987).- "Determination of some hydroxycholesterols in human serum samples".- J. Chromatorg. 416, 1-13.

Korahani, V., Bascoul, J. y Crastes de Paulet A. (1981).- "Capillary column gasliquid chromatographic analysis of cholesterol derivatives. Application to the autoxidation products of cholesterol".- J. Chromatogr. 211, 392-397.

Kou., I.L. y Holmes, R.P. (1985).-" "The analysis of 25-hydroxycholesterol in plasma and cholesterol containing foods by high performance liquid chromatography".- J. Chromatogr. 330, 339-346.

Lee, K., Herian, A.M. y Higley, A. (1985).- "Sterol oxidation products in french fries and in stored potato chips".- J. Food Prot. 48, 158-161.

Luby, J.M., Gray, J.I., Harte, B.R. y Ryan, T.C. (1986).- "Photooxidation of cholesterol in butter".- J. Food Sci. 51, 904-923.

Maerker, G. y Jones, K.C. (1992).- "Gamma-irradiation of individual cholesterol oxidation products".- J. Am. Oil Chem. Soc. 69, 451-455.

Maerker, G., Nungesser, E.H. y Zulak, I.M. (1988).- "HPLC separation and quantitation of cholesterol oxidation products whith flame ionization detection".- J. Agric. Food Chem. 36, 61-63.

Maerker, G. y Unruh, J. (1986).- "Cholesterol oxides. 1.Isolation and determination of some cholesterol oxidation products".- J. Am. Oil Chem. Soc. 63, 767-773.

Missler, S.R., Wasilchuk, B.A. y Merritt, C. (1985).- "Separation and identification of cholesterol oxidation products in dried egg preparations".J. Food Sci. 50, 595-598, 646.

Morgan, J.N. y Armstrong, D.J. (1987).- "Formation of cholesterol-5,6epoxides during Spray-drying of egg yolk".- J. Food Sci. 52, 1224-1227.

Morgan, J.N. y Armstrong, D.J. (1989).- "Wide-bore capillary gas chromatographic method for quantification of cholesterol oxidation products in egg yolk powder".- J. Food Sci. 54, 427-429, 457.

Morgan, J.N. y Armstrong, D.J. (1992).- "Quantification of cholesterol oxidation products in egg yolk powder spray-dried with direct heating".J. Food Sci. 57, 43-45, 107.

Naber, E.C., Allred, J.B., Winget, J. y Stock, A.E. (1985).- "Effect of cholesterol oxidation products on cholesterol metabolism in laying hen".- Poult. Sci. 64, 675-680.

Naber, E.C. y Biggert, M.D. (1985).- "Analisys for and generation of cholesterol oxidation products in egg yolk by heat treatment".- Poult. Sci. 64, 341-347.

Nawar, W.W., Kim, S.K., Li, Y.J. y Vadji, M. (1991).- "Measurement of oxidative interactions of cholesterol".- J. Am. Oil Chem. Soc. 68, 496-498.

Nourooz-Zadeh, J. y Appelqvist, L.-A. (1987).- "Cholesterol oxides in swedish foods and food ingredients: Fresh eggs and dehydrated egg products".- J. Food Sci. 52, 57-62, 67.

Nourooz-Zadeh, J. y Appelqvist, L.-A. (1988a). -"Cholesterol oxides in swedish foods and food ingredients: Butter and cheese".- J. Am. Oil Chem. Soc. 65, 1635-1641.

Nourooz-Zadeh, J. y Appelqvist, L.-A. (1988b).- "Cholesterol oxides in swedish foods and food ingredients: Milk powder products".- J. Food Sci. 53, 74-79, 87 . 
Nourooz-Zadeh, J. y Appelqvist, L.-A. (1989).- "Cholesterol oxides in swedish foods and food ingredients: Lard and bacon".- J. Am. Oil Chem. Soc. 66, 586-592.

Pannecoucke, X., Van Dorsselaer, A. y Luu B. (1992).- "Mass spectrometric studies of phospodiesters linked to oxysterols and nucleosids, a family of biologically potent oxygenated sterols".- Organic Mass Spectrometry 27, 140-144.

Park, S.W. y Addis, P.B. (1985a).- "Capillary column gas-liquid chromatographic resolution of oxidized cholesterol derivatives".- Anal. Biochem. 149, 275-283.

Park, S.W. y Addis, P.B. (1985b).- "HPLC determination of C-7 oxidized Cholesterol derivatives in foods".- J. Food Sci. 50, 1437-1441, 1444.

Park, S.W. y Addis, P.B. (1986a).- "Identification and quantitative estimation of oxidized cholesterol derivatives in heated tallow".- J. Agric. Food Chem. 34, 653-659.

Park, S.W. y Addis, P.B. (1986b).- "Further investigation of oxidized cholesterol derivatives in heated fats" - J. Food Sci. 51, 1380-1381.

Park, S.W. y Addis, P.B. (1987).- "Cholesterol oxidation products in some muscle foods".- J. Food Sci. 52, 1500-1503.

Park, S.W. y Addis, P.B. (1989).- "Derivatization of $5 \alpha$-cholestane-3ß,5,6ßtriol into trimethylsilyl ether sterol for GC analisys".- J. Am. Oil Chem. Soc. 66, 1632-1634.

Park, S.W. y Addis, P.B. (1992).- "Methods of analysis of cholesterol oxides" en "Biological effects of cholesterol oxides " p. 33-70.-S.K. Peng y R.J. Morin (Ed.).- CRC Press, Boca Raton-Ann Arbor-Londres.

Parks, O.W., Schwartz, D.P., Keeney, M. y Damico, J.N. (1966).- "Isolation of cholest-7-en-3-one from butterfat".- Nature. 210, 416-417.

Pennock, H.F. Neiss, G y Mahler, H.R. (1962).- "Developing avian embryo. V. Ubiquinone and some other unsaponifiable lipids".- Biochem. $J$. 85, 530-537.

Pie, J.E., Spahis, K. y Seillan, C. (1990).- "Evaluation of oxidative degradation of cholesterol in food and food ingredients: Identification and quantification of cholesterol oxides".- J. Agric. Food Chem. 38, 973979.

Pie, J.E., Spahis, K. y Seillan, C. (1991).- " Cholesterol oxidation in meat products during cooking and frozen storage".- J. Agric. Food Chem. 39 250-254.

Pie, J.E. y Seillan, C. (1992).- "Oxysterols in cultured bovine aortic smooth muscle cells and in the monocyte-like cell line".- Lipids 27, 270-274.

Prasad, C.R. y Subramanian, R. (1992).- "Qualitative and comparative studies of cholesterol oxides in commercial and home-made indian ghees".- Food Chem. 45, 71-73.

Ryan, T.C., Gray, J.I. y Morton, I.D. (1981).- "Oxidation of cholesterol in heated tallow". - J. Sci. Food Agric. 32, 305-308
Sander, B.D., Smith, D.E. y Addis, P.B. (1988).- "Effects of processing stage and storage conditions on cholesterol oxidation products in butter and cheddar cheese".- J. Dairy Sci. 71, 3173-3178.

Sander, B.D., Smith, D.E., Addis, P.B. y Park S.W. (1989).- "Effects of prolonged and adverse storage conditions on levels of cholesterol oxidation products in dairy products".- J. Food Sci. 54, 874-879.

Teng, J.I. (1990).- "Oxysterol separation by HPLC in combination with thin layer chromatography".- Chromatogram Noviembre, 8-10.

Teng, J.I. (1991).- "Column variations in the analysis of oxysterols using normal-phase high performance liquid chromatography".- LC-GC Intl. 4, 34-36.

Teng, J.I., Kulig, M.J. y Smith, L.L. (1973).- "Sterol metabolism. XXII. Gas chromatographic differentiation among cholesterol hydroperoxides".- $J$. Chromatogr. 75, 108-113.

Tsai, L.S. y Hudson, C.A. (1981).- "High performance liquid chromatography of oxygenated cholesterols and related compounds".- J. Am. Oil Chem. Soc. 58, 931-934.

Tsai, L.S. y Hudson, C.A. (1984).- "Cholesterol oxides in commercial dry egg products: Isolation and identification".- J. Food Sci. 49, 1245-1248.

Tsai, L.S. y Hudson, C.A. (1985).- "Cholesterol oxides in commercial dry egg products: Quantitation".- J. Food Sci. 50, 229-231, 237.

Tsai, L.S., ljichi, K., Hudson, C.A. y Meehan, J.J. (1980).- "A method for the quantitative estimation of cholesterol $\alpha$-oxide in eggs".- Lipids 15 , 124-128.

Van de Bovenkamp, P., Kosmeijer-schuil, T.G. y Katan, M.B. (1988)."Quantification of oxysterols in dutch foods: Egg products and mixed diets".- Lipids 23, 1079-1085.

Van Lier, J.E. y Smith, L.L. (1968).- "Sterol metabolism II. Gas chromatographic recognition of cholesterol metabolites and artifacs".Anal. Biochem. 24, 419-430.

Yan, P.S. y White, P.J. (1990).- "Cholesterol oxidation in heated lard enriched with two levels of cholesterol".- J. Am. Oil Chem. Soc. 67, 927-931.

Zubillaga, M.P. y Maerker, G. (1989).- "Cholesterol oxides III. Autoxidation of cholesterol in sodium stearate and sodium linoleate dispersions".- $J$. Am. Oil Chem. Soc. 66, 1499-1503.

Zubillaga, M.P. y Maerker, G. (1991).- "Quantification of three cholesterol oxidation products in raw meat and chicken".- J. Food Sci. 56, 11941202.

Zhang, W.B. y Addis, P.B. (1990).- "Prediction of levels of cholesterol oxides in heated tallow by dielectric measurement".- J. Food Sci. 55, 1673-1675.

Zhang, W.B., Addis, P.B. y Krick, T.P. (1991).- "Quantification of $5 \alpha-$ cholestane-3ß,5,6ß-triol and other cholesterol oxidation products in fast food french fried potatoes".- J. Food Sci. 56, 716-718.

(Recibido: Enero 1994) 